\title{
Gonadotropin-releasing Hormone (GnRH)-Immunoreactive Terminal Nerve Cells Have Intrinsic Rhythmicity and Project Widely in the Brain
}

\author{
Yoshitaka Oka and Toshiya Matsushima ${ }^{a}$ \\ Zoological Institute, Faculty of Science, University of Tokyo, Hongo, Tokyo 113, Japan
}

Modulation of ionic channel properties and synaptic functions by neurotransmitters and hormones is called neuromodulation and may be the basis for many long-lasting changes in animal behavior, for example, changes in the arousal or motivational states. We have previously shown in a teleost, the dwarf gourami, that the terminal nerve (TN) cells are a major component of the gonadotropin-releasing hormone (GnRH) system and are structurally independent from the preoptic/hypophysial-GnRH system, which projects to the pituitary and facilitates gonadotropin release from the gonadotropes. While GnRH fibers originating from TN cells are distributed widely throughout the brain, they do not project to the pituitary. Thus, TN-GnRH system does not function as a hypophysiotropic hormone but probably as a neuromodulator, capable of affecting widespread regions of the brain.

In the present study, we used a whole-brain in vitro preparation to examine the spontaneous electrical activities of TN-GnRH cells and to determine the morphology of individual cells by intracellular injections of either neurobiotin or biocytin. The recorded cells were clearly identified as GnRHimmunoreactive TN cells by using combined intracellular injection and GnRH immunocytochemistry. Most of the TN cells showed endogenous slow (1-7 Hz), regular beating discharges. The intrinsic nature of this activity was demonstrated by the voltage dependency of the beating frequency, rhythm resetting, and persistence of rhythmicity after synaptic isolation. Only a small number of TN cells showed either irregular or bursting discharge patterns. Anatomical observation of intracellularly labeled cells showed that, regardless of discharge patterns, all the TN cells had multiple axonal branches that project to those areas where we had previously demonstrated dense GnRH-immunoreactive fibers.

From the present results, we propose a hypothesis that may be relevant to the peptidergic and monoaminergic neuromodulatory systems in general. The modulator neurons have endogenous rhythmic activities that vary according to

\footnotetext{
Received Sept. 3, 1992; revised Nov. 17, 1992; accepted Nov. 23, 1992.

We thank Dr. J. G. McHaffie for his critical reading of the manuscript, Dr. Y. Kubo for advice and discussion, Dr. T. Hasegawa for his custom-made devices, and Dr. S. Kamimura for his technical advice. We also thank Prof. S. Kawashima and Prof. K. Aida for their encouragement and financial support. This work was supported by the Ministry of Education, Science and Culture of Japan.

Correspondence should be addressed to Yoshitaka Oka at the above address.

aPresent address: Life Science Institute, Sophia University, Kioi-cho, Chiyoda, Tokyo 102, Japan.

Copyright (C) 1993 Society for Neuroscience $0270-6474 / 93 / 132161-16 \$ 05.00 / 0$
}

the animal's hormonal or environmental conditions, and they regulate the excitability of target neurons in a wide variety of brain regions simultaneously via multiple axonal branches.

[Key words: gonadotropin-releasing hormone (GnRH), terminal nerve, neuromodulation, intracellular recording, intracellular staining, neurobiotin, biocytin, in vitro preparation]

Since the advent of the immunosytochemical techniques, our understanding of the chemoarchitecture of the brain has greatly advanced (Nieuwenhuys, 1985). One of the most interesting and important findings may be that various hormone-like substances are also present in the brain. Nevertheless, the functional significance of such hormone-like substances in the brain is still only poorly understood. The gonadotropin-releasing hormone $(\mathrm{GnRH})$ is one such substance. It was originally purified and identified as a hypophysiotropic hormone that facilitates gonadotropin release from the pituitary. After some technical improvements, it became possible to localize GnRH-immunoreactive ( $\mathrm{GnRH}$-ir) cell bodies as well as to detail the distribution of fibers in intact brain preparations by immunocytochemistry (see Silverman, 1988, for review). The GnRH-ir system of vertebrates is mainly divided into the septo-preoptico-infundibular pathway and the extrahypothalamic projections. Schwanzel-Fukuda and Silverman (1980) first reported that the rostral extrahypothalamic GnRH-ir cell groups belong to the terminal nerve (TN). Since then, the GnRH-ir TN system has been recognized in all vertebrate species reported to date (see Demski and Schwanzel-Fukuda, 1987). We have previously shown in a teleost, the dwarf gourami, that TN cells are a major component of the GnRH system and are structurally independent from the preoptic/hypophysial-GnRH system. The latter is homologous to the septo-preoptico-infundibular pathway of mammals and facilitates gonadotropin release from the pituitary. Thus, GnRH originating from TN cells does not function as a hypophysiotropic hormone but rather as a neuromodulator (Oka and Ichikawa, 1990; Yamamoto et al., 1991). In fact, GnRH has been suggested to act as a neuromodulator in peripheral ganglia (Brown, 1983, 1988; Joncs, 1987) and CNS (Wong ct al., 1990) by inhibiting time- and voltage-dependent $\mathrm{K}^{+}$current, the M-current.

Although there has recently been much interest on the modulation of ionic channel properties by neurotransmitters and hormones (Kaczmarek and Levitan, 1987; Hille, 1992), there is very limited information on the morphological and physiological characteristics of individual modulator neurons per se. In the present study, we have taken advantage of the fact that the entire brain of the dwarf gourami can be maintained in in 
vitro conditions for relatively long periods of time (Oka, $199 \mathrm{la}, \mathrm{b}$, 1992). Furthermore, the TN-GnRH cells of the dwarf gourami can be easily identified as a distinct structure of cells clustered immediately beneath the ventral meningeal membrane, thus facilitating easy and stable intracellular recording in the ventralside-up in vitro brain preparation. We examined both the spontaneous electrical activity of $\mathrm{TN}$ cells by intracellular recording and the morphology of individual cells by intracellular staining and have determined that TN-GnRH cells possess the prerequisite characteristics necessary to function as a presumptive neuromodulator. We also propose a general hypothesis regarding peptidergic and monoaminergic modulator neurons.

Preliminary accounts of some of these results have appeared in abstract form (Oka, 1991a,b), and a short report of some of the present results has been published elsewhere (Oka, 1992).

\section{Materials and Methods}

In vitro preparation. A small tropical fish, the dwarf gourami (Colisa lalia), whose TN-GnRH cells have been well characterized morphologically (Oka and Ichikawa, 1990, 1991, 1992), was used. Adult male and female dwarf gouramis, about $4 \mathrm{~cm}$ in standard length, were purchased from a local dealer and were kept at $27^{\circ} \mathrm{C}$ until used. The fish were anesthetized by immersing them in crushed ice. The whole brain was dissected out from a decapitated fish and was pinned ventral side up to the Sylgard base of a small recording chamber. This "whole-brain preparation" was continuously superfused with standard oxygenated Krebs-Ringer solution (Llinàs and Sugimori, 1980). The temperature of the perfusing solution was regulated at $20^{\circ} \mathrm{C}$ by placing the chamber on a thermoregulator device. Body weights and gonad weights were measured, and the gonadosomatic index was calculated in each fish (indicated as gonad weight/body weight $\times 100 \%$ ).

Electrical recording. The intracellular recording electrodes were filled with either 5\% biocytin (Horikawa and Armstrong, 1988) (Sigma) in 0.5 M KCl or $2 \%$ neurobiotin (Kita and Armstrong, 1991) (Vector) in $2 \mathrm{M} \mathrm{KCl}$. The impedance of the microelectrodes was usually 50-90 M . Signals were amplified by a two-channel bridge current-clamp amplifier (MEZ-8300, Nihon Kohden, Tokyo). Records of voltage and current were stored on a TEAC PCM data recorder (RD-101T) for off-line analysis. The data were filtered at $3 \mathrm{kHz}$, digitized at $2-10 \mathrm{kHz}$ by a personal compuler equipped with an A/D converter (ADX-98H, Canopus, Kobe). The digitized data were analyzed and edited by SIGNAS and WAVEMASTER II software programs (Canopus, Kobe), and drawn using a pen plotter (Graphtec, MP4400). The input resistance of the cells were calculated from the slope of the linear regression curve of the $I-V$ plots, which had been obtained by recording voltage deflections in response to $100 \mathrm{msec}, 0.1 \mathrm{nA}$ step current pulses from -1.0 to $0.5 \mathrm{nA}$. When necessary, the recorded signals were averaged by using an analog trigger controller (ADT-98E, Canopus). In four fish, TN cells were also extracellularly recorded. Glass microelectrodes with partially broken tips were filled with $2 \mathrm{M} \mathrm{NaCl}$ (DC resistance, 15-20 M $)$ ). The signals were amplified by the same amplifier used for the intracellular recording and then a custom-made amplifier; these were processed similarly as in the intracellularly recorded ones. Values are expressed as means \pm SEM.

Intracellular staining. After the electrophysiological recordings, the neurons were injected with either biocytin (1-5 nA of either depolarizing or hyperpolarizing $D C$ current with $100 \mathrm{msec}$ pause per second) or neurobiotin (same amount of depolarizing current) for 1-10 min. Resting potentials and spiking activities were monitored during the pause, and the current injection was terminated before the units deteriorated in order to avoid leakage of dyes. One minute of injection was usually enough. After the injections, the brains were kept in the chamber for various time periods to allow for the biotin complexes to diffuse. Survival time of as short as $15 \mathrm{~min}$ gave satisfactory results. The brains were fixed for $1-2 \mathrm{~d}$ in $10 \%$ paraformaldehyde containing $10 \%$ sucrose. Longer fixation time appeared to reduce the background staining. After embedding in $15 \%$ gelatin dissolved in phosphate buffer (PB), the specimens were quickly frozen wilh powdered dry ice. Serial frozen sections were cut at $64 \mu \mathrm{m}$ on a cryostat. Most samples were cut sagittally; a few were cut either frontally or horizontally. The free-floating sections were treated as follows, at room temperature: (1) rinsed in $0.1 \mathrm{M}$ phosphate buffer containing $0.7 \% \mathrm{NaCl}$ and $0.3 \%$ Triton $\mathrm{X}-100$ (PBST) and then immersed in $3 \% \mathrm{H}_{2} \mathrm{O}_{2}$ in PBST for 10 min to block endogenous peroxidase activities; $(2)$ rinsed three times and immersed in PBST overnight to make the sections permeable to the reagents; (3) rinsed in PBST and incubated in HRP-conjugated streptavidin (Nichirei) for $30 \mathrm{~min}$; (4) rinsed three times in PBST and incubated in diaminobenzidine (DAB) solution $\left(50 \mathrm{mg}\right.$ of $\mathrm{DAB}+3 \mathrm{ml}$ of $0.3 \% \mathrm{H}_{2} \mathrm{O}_{2}$ in $100 \mathrm{ml}$ of 0.1 M PB) for 5-10 min; (5) rinsed three times in $0.1 \mathrm{M} \mathrm{PB}$; (6) mounted on gelatinized slides and dried; and (7) dehydrated and coverslipped.

Some neurons injected with neurobiotin were further double labeled for GnRH immunocytochemistry using Texas red (TR) and fluorescein isothiocyanate (FITC) as fluorescent markers. For this purpose, the brains were fixed in a fixative for immunocytochemistry (Oka and Ichikawa, 1990) for $2 \mathrm{~d}$ and wcre cut at $48 \mu \mathrm{m}$. The free-floating sections were treated as follows, at room temperature: (1) rinsed three times in PBST and incubated in monoclonal antibody against GnRH (LRH13; see Oka and Ichikawa, 1990) overnight; (2) after a thorough rinse in PBST, incubated in streptavidin-TR conjugate (GIBCO/Bethesda Research Laboratories; diluted 360 times) for $1.5 \mathrm{hr}$ and rinsed three times in PBST; (3) incubated in biotinylated anti-mouse IgG for $30 \mathrm{~min}$ and rinsed three times in PBST; (4) incubated in streptavidin-FITC conjugate (Biomeda; diluted 20 times) for $1.5 \mathrm{hr}$ and rinsed in $\mathrm{PB}$; and (5) mounted in glycerol and coverslipped.

Under this procedure, neurobiotin-injected cell bodies and fibers were labeled with TR, while GnRH-ir cell bodies and fibers were labeled with FITC. The sections were observed under epifluorescent microscopy for the presence of both neurobiotin labeling and GnRH immunoreactivity, using $\mathrm{G}$ exciter filter combination for $\mathrm{TR}$ and $\mathrm{B}$ combination for FITC.

The intracellularly labeled cell bodies and fibers were drawn with the aid of a camera lucida. They were reconstructed and illustrated on a representative parasagittal or frontal sections. In the early part of the experiments, Lucifer yellow was also used ( 25 units). Microelectrodes filled with $5 \%$ Lucifer yellow CH dilithium salt (Sigma) dissolved in distilled water (DC resistance, 130-200 M 2 ) were injected by hyperpolarizing current pulses with similar parameters as in biotin injections. After fixation, the brains were cut serially at $50 \mu \mathrm{m}$ on a cryostat. The sections were thaw mounted on slides, dried, and coverslipped by using glycerol-gelatin. They were observed under epifluorescent microscopy with $\mathrm{G}$ exciter filter.

\section{Results}

The TN-GnRH cells are by far larger than the other cells in telencephalic areas and form a distinct structure of cells clustered beneath the meningeal membrane (Oka et al., 1986; Oka and Ichikawa, 1990, 1991). Therefore, they could be easily penetrated from the ventral side with the aid of a dissecting microscope. The cells were penetrated at depths immediately beneath the meningeal membrane (about $50 \mu \mathrm{m}$ in thickness) up to 200 $\mu \mathrm{m}$ from the ventral surface. The data presented below were obtained from $158 \mathrm{TN}-\mathrm{GnRH}$ cells of 102 fish brains in vitro. Most of the intracellularly recorded units were stained after recording, and could be morphologically identified as type I TN cells (Oka et al., 1986; Oka and Ichikawa, 1991), which are known to be immunoreactive to GnRH (Oka and Ichikawa, 1990, 1992). Because all the recorded units showed spontaneous discharges, the measurement of true resting potentials was difficult. Therefore, the value of the membrane potential at the start of rising phase of membrane potential oscillations was operationally defined as the resting potentials. Units with such resting potentials negative to $-30 \mathrm{mV}$ were used for the electrophysiological analysis $(-46 \pm 9 \mathrm{mV}, n=118)$. They had mean input resistance of $90 \pm 24 \mathrm{M} \Omega(n=15)$. Units with resting potentials less negative than $-30 \mathrm{mV}$ (32 units) could also be injected with dyes and gave satisfactory labeling. Eight units were recorded extracellularly.

\section{Types of spontaneous discharges}

All the TN units recorded in the present study showed spontaneous electrical activities. They were tentatively classified into 

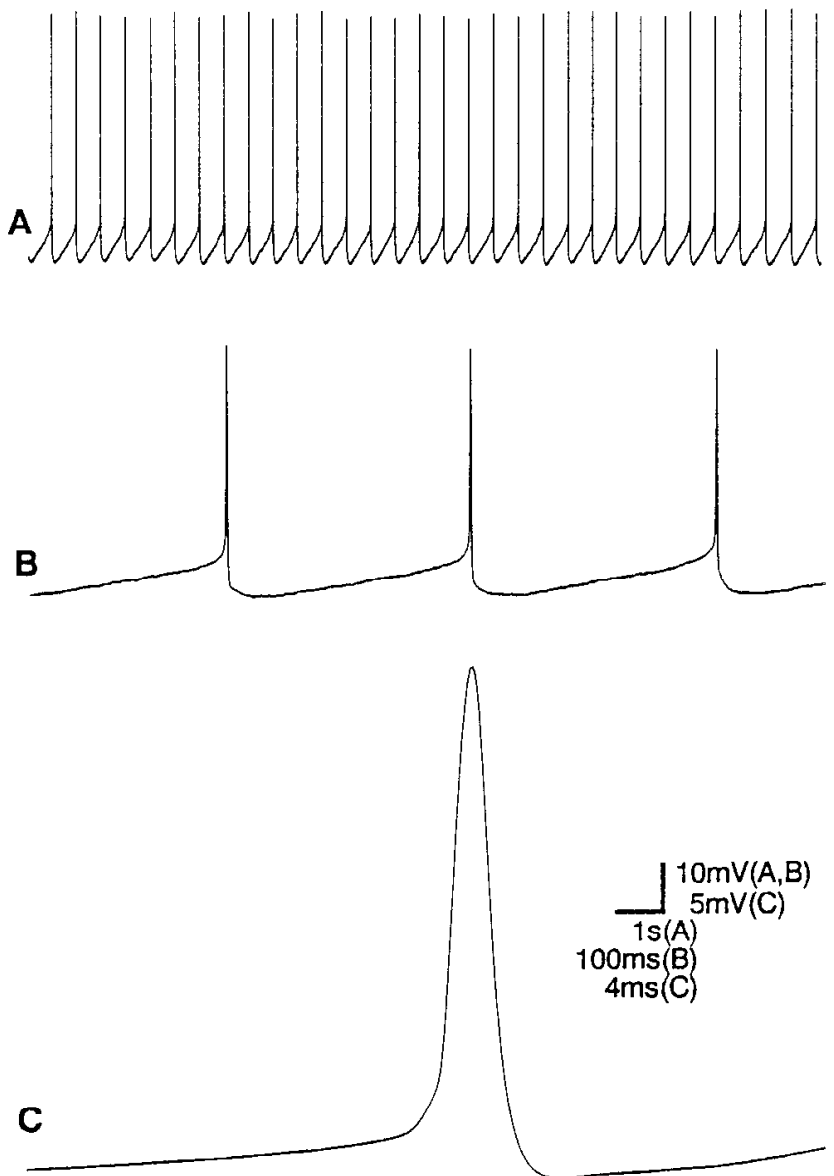

Figure 1. Typical example of beating discharge mode recorded intracellularly. $A$ and $B$ show recordings from the same cell on different time scales. They are beating at about 2 spikes/sec with very regular interspike intervals. During interspike intervals, smooth and gradual depolarizations are prominent and there are no clear synaptic potentials $(B) . C$ shows a spike averaged from 30 traces. The spike duration is long, and the fast afterhyperpolarizing potential is not prominent compared with irregular mode (Fig. 2).

three types of discharges: beating, irregular, or bursting (Figs. $1-3$ ). It should be emphasized, however, that the morphologies of each category were fundamentally the same (see below). This suggests that different types of discharges do not arise from different subtypes of TN-GnRH cells but rather that TN-GnRH cells may be able to shift from one type of discharge pattern to another, dependent on physiological conditions of the fish (see Discussion).

Beating discharges. Eighty-three percent (98 of 118 units in 72 of 81 fish) of the units analyzed in the present study showed a very regular spontaneous beating discharge pattern (Figs. 1, 4-7; see Fig. 9). The percentage became a little higher when other units with smaller resting potentials were taken into account, because almost all of the latter also showed regular membrane potential oscillations. Typical examples of beating discharges recorded intracellularly are shown in Figures 1 and 47. They are characterized by very regularly paced slow ( $3.7 \pm$ 1.3 spikes $/ \mathrm{sec}, n=91$; range, $0.9-6.7$ ) beating discharges. The spikes are sometimes observed as doublets or even triplets (Figs. $4 A, 5 A$ ). Spike durations were usually long, but were variable among different preparations $(9.1 \pm 3.6 \mathrm{msec}, n=28$; range, 4.8-19.2 msec; measured from the start of the rising phase of
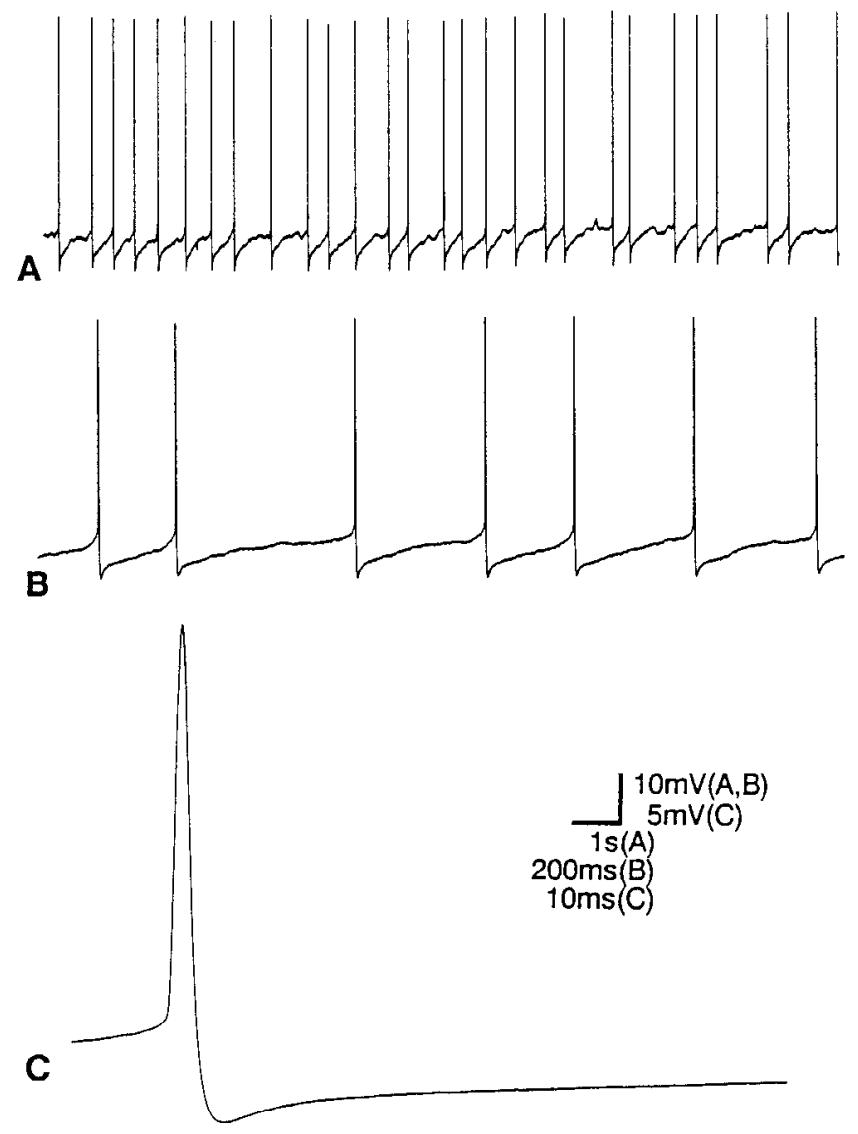

Figure 2. Typical example of irregular discharge mode. $A$, The interspike intervals are variable in length and are not smooth as in beating mode (Figs. 1, 4-7). This mode is characterized by prominent fast afterhyperpolarizations following the spikes $(A-C)$, which are not evident in the beating discharge mode. $C$ shows a spike averaged from 30 traces. The spike durations are shorter than the beating mode, and the fast afterhyperpolarizing potentials are prominent.

spikes averaged from 30 traces; see Fig. 1C). The interspike intervals were characterized by smooth and gradual depolarizations, and no clear synaptic potentials were evident (Fig. 1A,B).

Irregular discharges. Other types of spontaneous discharges were also observed in TN-GnRH cells, although they were encountered far less frequently. Eleven percent of the units (13 of 118 units in 6 of 81 fish) showed irregular spontaneous discharges (Fig. $2 A-C$ ). The percentage became much smaller when other units with smaller resting potentials were taken into account, because almost all of the latter showed regular beatingtype membrane potential oscillations. This type of discharge was characterized by prominent fast afterhyperpolarizations following the spikes, which are not always evident in the beating discharge mode. Another feature is the small irregular voltage fluctuations during the interspike intervals (Fig. $2 A$ ). Spike durations ( $7.1 \pm 1.1 \mathrm{msec}, n=9$; range, $5.4-9.4 \mathrm{msec}$ ) were shorter compared with that of the beating discharges $(p<0.1$, Student's $t$ test).

Bursting discharges. Others ( 7 of 118 units in 3 of 81 fish) displayed spontaneous bursting with prominent interburst silent periods (Fig. $3 A-C$ ). The unit in Figure 3 was bursting at about $10 \mathrm{sec}$ intervals with interburst periods of about $2 \mathrm{sec}$. Figure $3 B$ shows an expanded trace of the beginning of burst, which shows an acceleration of spiking frequency. Another feature of 

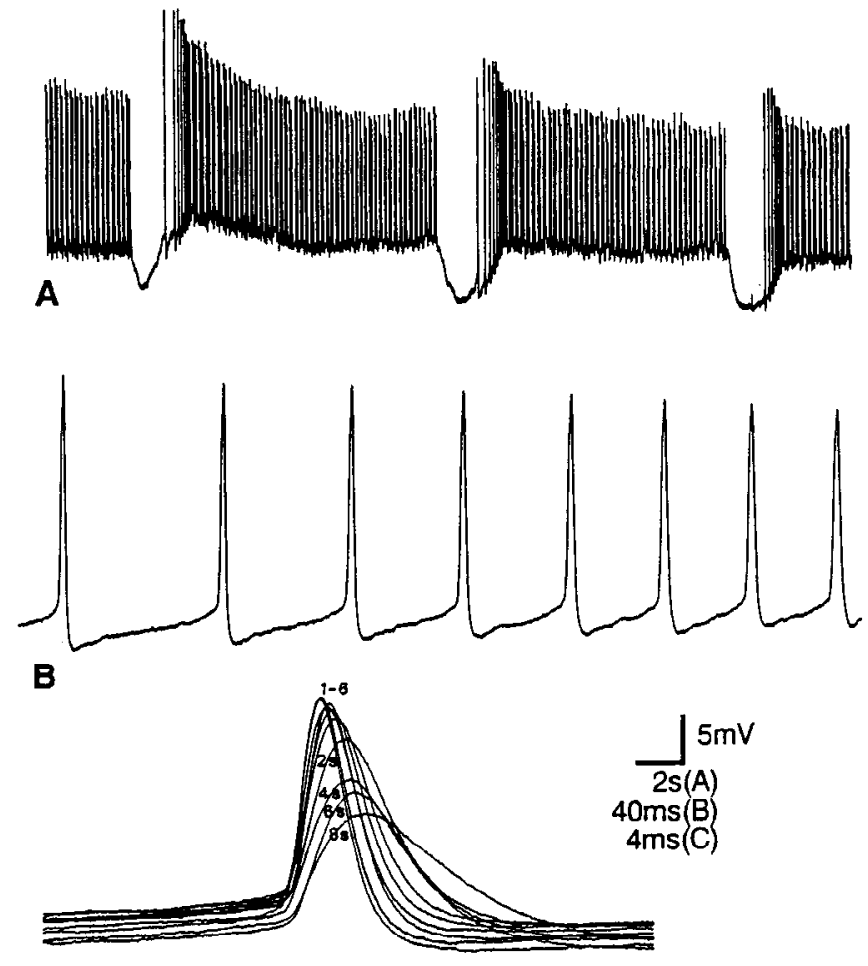

C

Figure 3. Typical example of bursting discharge mode. A, This unit is bursting at about $10 \mathrm{sec}$ intervals with interburst periods of about 2 sec. $B$ shows an expanded trace of the beginning of burst, which shows an acceleration of spiking frequency. The action potentials during the burst shows progressive broadening $(C)$. The traces labeled $1-6$ indicate first to sixth action potentials in the burst, and the other traces are 2, 4,6 , and $8 \mathrm{sec}$ after the onset of the burst.

this bursting pattern is the progressive broadening of the action potentials during the burst (Fig. $3 C$ ).

\section{Intrinsic nature of beating discharges}

In order to demonstrate that the beating rhythm is intrinsic to the TN cells and is not driven synaptically from other pacemaker neurons, we examined whether the TN cells that showed beating discharges fulfill the following three criteria (cf. Alving, 1968; Benson and Adams, 1989): (1) dependency of discharge frequencies on the injected DC currents, (2) rhythm resetting by exogenously applied current pulses, (3) persistence of pacemaker activities under synaptically isolated conditions.

First, the frequency of both full-spike and subthreshold beating discharges was increased by a depolarizing DC current injection but was decreased by a hyperpolarizing current injection (Fig. 4). The TN cell shown in Figure $4 A$ was discharging full spikes in a beating mode with the spikes occurring as doublets. Not only did injection of a $0.3 \mathrm{nA}$ depolarizing current change the spikes from doublets to triplets, but it also increased the frequency of spike pairs. In contrast, hyperpolarizing currents of 0.3 and $0.5 \mathrm{nA}$ made the spikes singlets and decreased the spike frequency. The relationship between injected currents and spike frequencies in another cell is illustrated in Figure $4 B$. The relationship was almost linear in the current range used in the present experiment. The frequency of subthreshold membrane potential oscillations were also modified by current injections in a similar manner (Fig. $4 C$ ). These observations also support the notion that the subthreshold membrane potential oscilla- tions are pacemaker activities without somatic spikes (see above). It may be further argued that the subthreshold oscillations are not EPSPs evoked by inputs from other pacemakers because the frequency of extrinsic EPSPs would not be modulated by current injections to the recorded cells.

Second, brief hyperpolarizing current pulses reset the beating rhythm (Fig. $5 A, B$ ). The TN cell shown in Figure $5 A$ was discharging full-spike doublets or triplets in a beating mode. Brief $(100 \mathrm{msec})$ hyperpolarizing current pulses $(0.7-0.9 \mathrm{nA})$ evoked anode break spikes in these cells. The arrowheads indicate normal occurrence of spikes predicted from undisturbed intact activities. After the current pulses, a new beating cycle is started at the normal cycle period, established not from the preceding spikes but from the imposed anode break spikes. That is, the beating rhythm is reset by the current pulse injections. Similarly, the subthreshold membrane potential oscillations were also reset by current pulse injections (Fig. $5 B$ ). In this case, hyperpolarizing current pulses of 1 nA did not evoke anode break spikes, but the peak of the voltage deflection immediately following current pulses was delayed compared to the timing predicted from undisturbed intact activities (arrowheads).

Third, when TN cells were synaptically isolated from other neurons by adding $3 \mu \mathrm{M}$ TTX to the perfusing solution, the action potentials disappeared, but small subthreshold membrane potential oscillations still remained (Fig. 6). These subthreshold oscillations were quite similar to those observed in normal perfusing solutions (Figs. $4 C, 5 B, 7 B$ ).

Taken together, these results clearly indicate that the spontaneous beating rhythm of the TN-GnRH cells is not driven synaptically from other pacemaker cells but is endogenous to these cells, and furthermore, that the small membrane potential oscillations recorded in the soma (Figs. $4 C, 5 B, 6 B, 7 B$ ) are not EPSPs but "pacemaker potentials" that originate from intrinsic properties of the ion channels of the TN-GnRH cells. In addition, the pacemaker activities of the TN cells are not sensitive to TTX, which may suggest an involvement of low-voltageactivated $\mathrm{Ca}^{2+}$ current (cf. Connor, 1985; Grace and Onn, 1989; Aghajanian, 1990; Sànchez and Ribas, 1991; Yung et al., 1991) or TTX-resistant persistent $\mathrm{Na}^{+}$current (Alreja and Aghajanian, 1991; Raggenbass et al., 1991) in the generation of pacemaker potentials. This point should be clarified in future studies. Although the pacemaker potentials were evident in most of the beating TN units as smooth and gradual depolarizations during interspike intervals (Fig. $1 A, B$ ), some showed less steep pacemaker potentials (Fig. $7 A, B$ ). In these cases, the spikes displayed inflections in their rising phase (Fig. $7 B, C$, arrowheads), and the spikes often failed at these inflections (Fig. $7 B$ ). It should be noted that the frequency of pacemaker potentials is the same regardless of the occurrence of action potentials (compare Fig. $7 A, B$; see also Fig. $6 A, B$ ). Furthermore, $41 \%$ (40 of 98 units) of the beating units showed only subthreshold membrane potential oscillations with less steep pacemaker potentials (e.g., Fig. $4 C$; resting potential $=-53 \mathrm{mV}$ ). These observations clearly indicate that the pacemaking mechanism and the action potential generation are independent. The subthreshold membrane potential oscillations may be regarded as pacemaker activities in the absence of somatic spikes (see Junge and Moore, 1966; Tauc, 1966). The failure of somatic spikes may be related to the excitabilities of the TN soma.

Because the occurrence of irregular and bursting discharges was low, the nature of these discharges could not be further analyzed in the present study. 

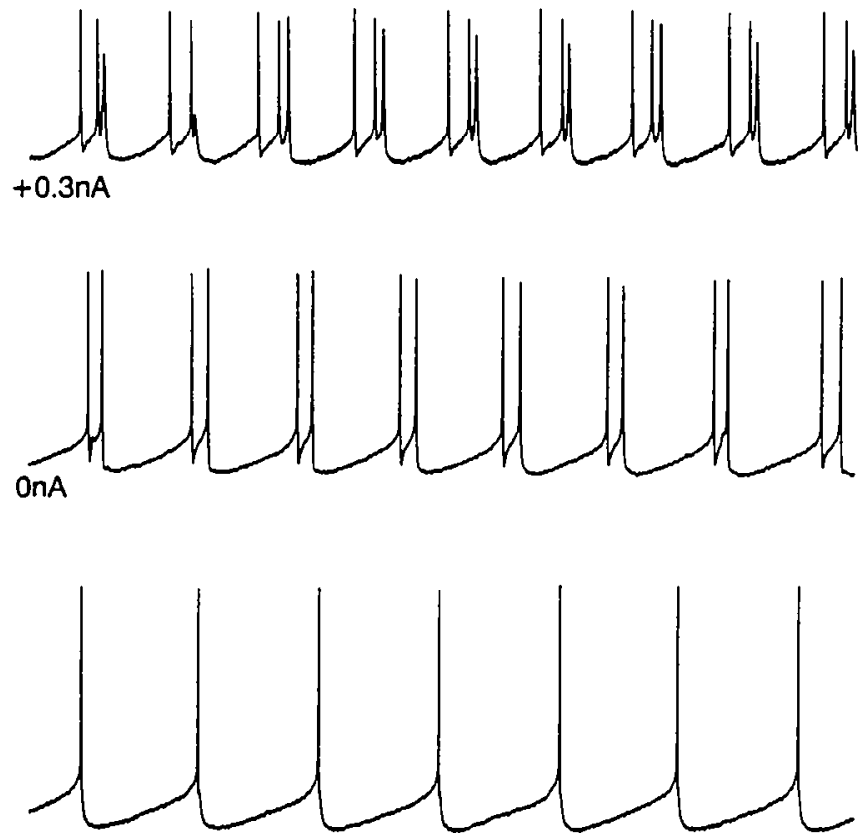

$-0.3 n A$

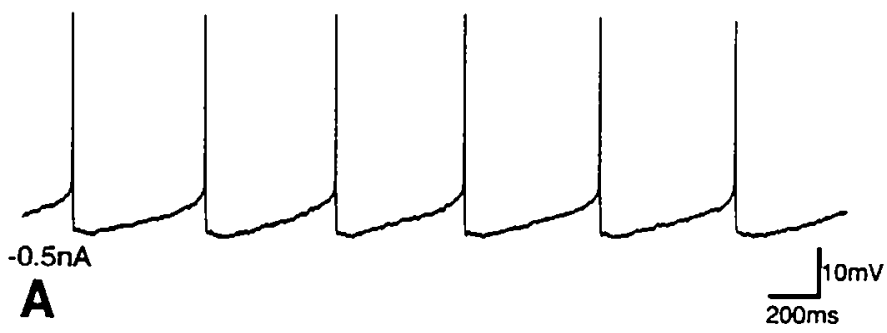

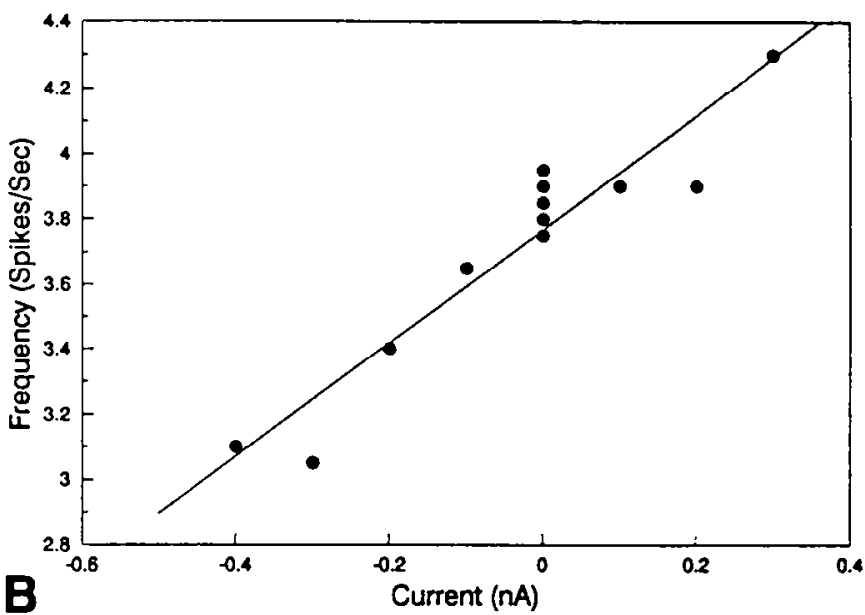
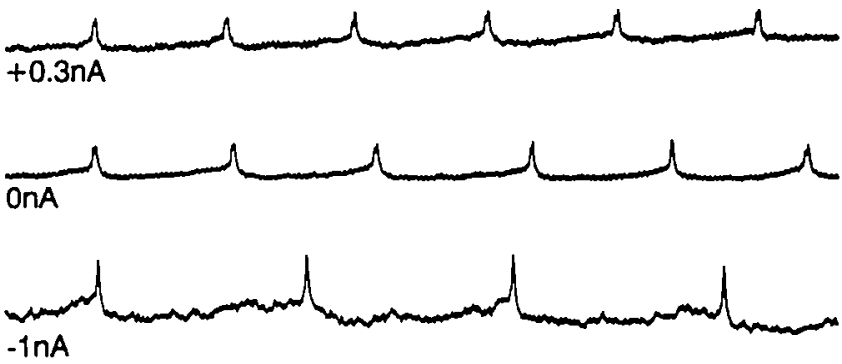

C

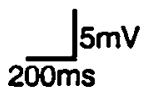

Figure 4. The frequency of beating depends on the injected DC currents. The cell in $A$ is discharging full spikes in a beating mode, and the spikes occurred as doublets. A depolarizing current of $0.3 \mathrm{nA}$ made the spikes triplets and increased the frequency of spike pairs. Hyperpolarizing currents of 0.3 and $0.5 \mathrm{nA}$ made the spikes singlets and decreased the spike frequency. The relationship between injected currents and spike frequencies in another cell is plotted in $B$. The relationship is almost linear in the current range used in the present experiment. The frequency of subthreshold membrane potential oscillations $(C)$ was also modified by current injections in a similar manner as in $A$ and $B$.

\section{Spontaneous discharge frequencies and modes}

The frequency of beating discharges ranged from 0.9 to $6.7 \mathrm{~Hz}$. (see above) and varicd among different fish. In some intracellular recordings in which several different units were recorded from the same preparations, correlation between frequencics of different units (faster and slower) was examined (Fig. 8). The correlation coefficient $(r)$ of the faster and slower units in the same preparation was $0.92(Y=0.95 X-0.43)$, which suggests that the different units recorded from the same preparation show similar discharge frequencies. This correlation was also observed in extracellular recordings. Figure 9 shows an extracellularly recorded units displaying a beating discharge pattern. As shown in records in Figure 9, $A$ and $B$, different units recorded from the same preparation usually showed similar frequencies of discharges. This situation is also evident in recordings where activities of two adjacent units are simultaneously recorded (Fig. $9 B$, larger and smaller spikes, expanded in $\left(C^{\prime}\right)$; these two units discharge at similar frequencies. It should also be noted that they are not phase locked nor are they discharging synchronously. From these results, it may be hypothesized that the frequencies of beating discharges are related to the physiological conditions of the fish. They were not, however, related to the sexual difference.

Another important finding is that the type of spontaneous discharge was similar among different units recorded from the same preparation. For example, once a beating unit is recorded, all the other units recorded in the same fish were also beating units with similar frequencies (in 15 of 15 such cases; Fig. 8; see also Fig. $9 A, B$ ). Similarly, once an irregular unit is recorded, all the other units recorded in the same fish were also irregular units (in 4 of 4 such cases). This was also true for the bursting units (in 2 of 2 such cases). It should be stressed again, however, that the morphologies of all these units were fundamentally the same (see below). This indicates that different discharge modes do not arise from different subtypes of TN-GnRH cells. Thus, it may be hypothesized that TN-GnRH cells can shift from one discharge mode to another, dependent on physiological conditions of the fish.

\section{Morphology of intracellularly labeled TN-GnRH cells}

After recording, the cells were injected with either Lucifer yellow or biotin complex (biocytin or neurobiotin), and their morphology was examined (Figs. 10-15). We found out that the 

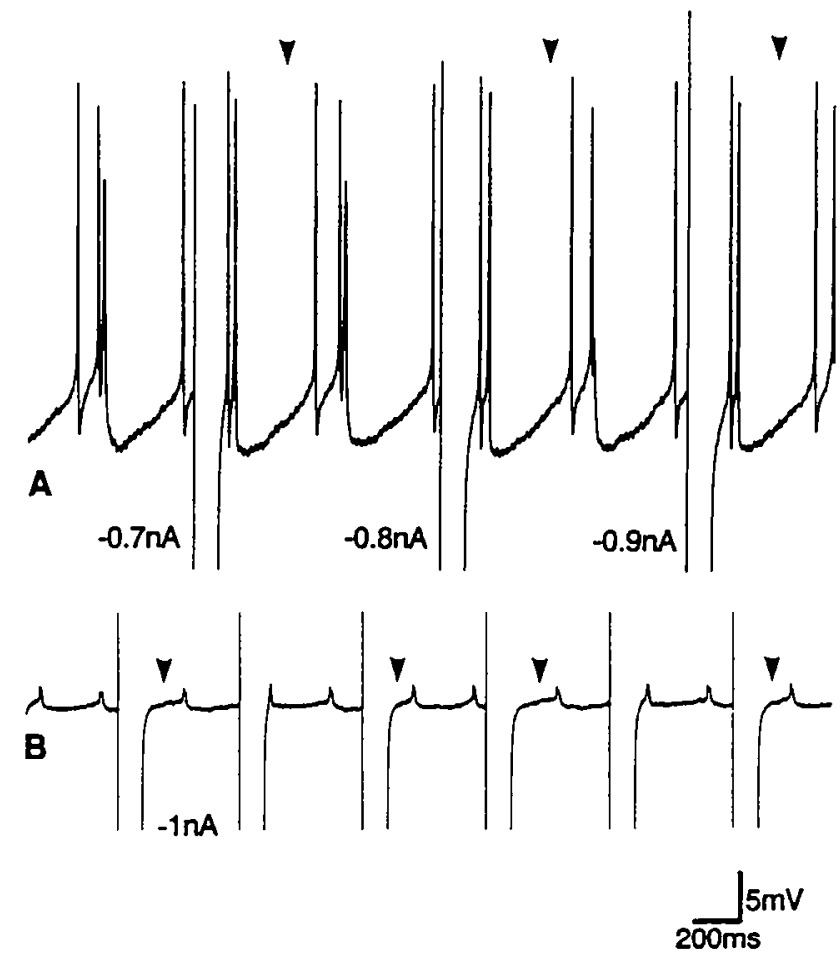

Figure 5. The beating rhythm is reset by brief hyperpolarizing current pulses. The cell in $A$ is discharging full-spike doublets or triplets in a beating mode. Brief $(100 \mathrm{msec})$ hyperpolarizing current pulses $(-0.7$ to $0.9 \mathrm{nA}$ ) evoked anode break spikes in these cells. The arrowheads indicate normal occurrence of spikes predicted from undisturbed intact activities. After the current pulses, new beating cycle starts at a normal cycle period, not from the preceding spikes but from the imposed anode break spikes. Similarly, the subthreshold membrane potential oscillations were also reset by current pulse injections $(B)$. In this case, hyperpolarizing current pulses of $1 \mathrm{nA}$ did not evoke anode break spikes, but the peaks of the membrane potential oscillations immediately following current pulses were delayed compared to the timing predicted from undisturbed intact activities (arrowheads).

biotin complexes, biocytin (Horikawa and Armstrong, 1988) and neurobiotin (Kita and Armstrong, 1991), give far superior labeling than Lucifer yellow, and that they are suited for reconstruction of labeled profiles from serial sections. We could detect no differences between the sensitivity of biocytin and neurobiotin. Therefore, the following description is based on findings using the biotin complexes. In addition, some neurobiotin-injected cells were double labeled for GnRH immunocytochemistry using TR and FITC as fluorescent markers (Fig. 10C-F). Figure $10, C$ and $E$, shows neurobiotin-injected TR-labeled cell body and fibers, while Figure $10, D$ and $F$, shows GnRH-ir FITC-labeled cell bodies and fibers demonstrated on the same sections (Fig. 10, C,D and $E, F$ are identical sections, respectively). The arrows in Figure $10 C-F$ show double-labeled profiles. Other fluorescent profiles in Figure 10, $D$ and $F$, are GnRHir fibers that were not injected with neurobiotin. Thus, the intracellularly recorded and labeled neurons could be definitely identified as GnRH-ir TN cells.

Although there were some minor variations, the morphologies and projection patterns of all intracellularly labeled TN-GnRH cells were similar. Furthermore, we could not establish any correlation between morphology and spontaneous discharge patterns. Cell bodies (Figs. 10A, 11) ranged from 20 to $30 \mu \mathrm{m}$ in diameter and had irregular contour and numerous fine somatic

\section{Control}
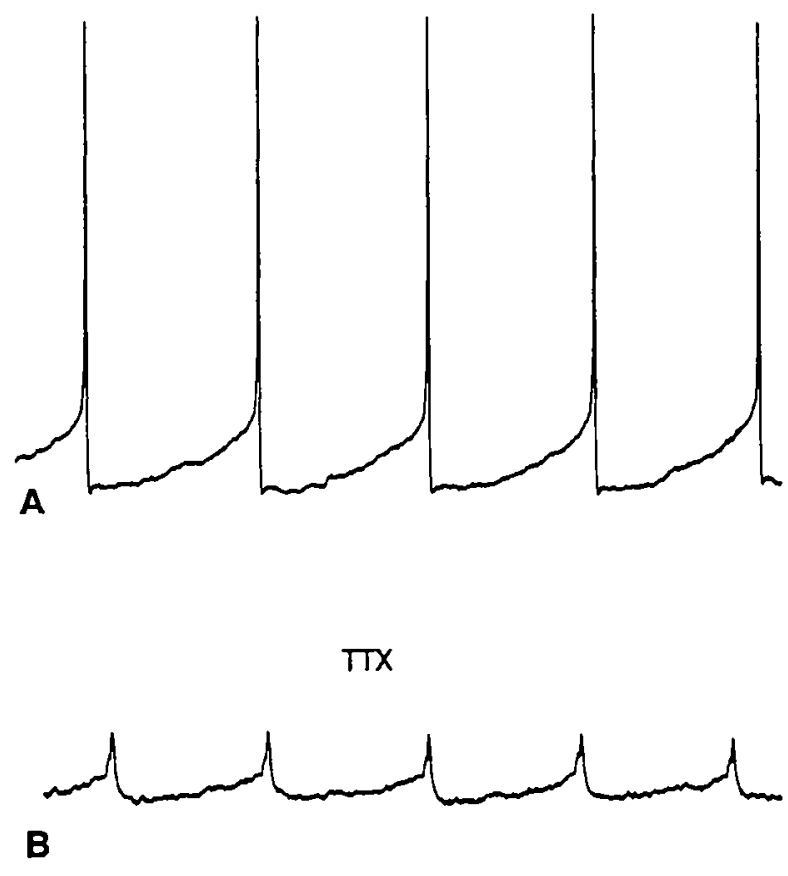

Figure 6. The pacemaker activities persisted under synaptically isolated conditions. $A$ shows normal beating discharges in the standard solution. The cells were synaptically isolated from each other by adding

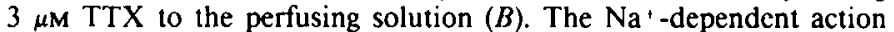
potentials of TN cells disappeared, but small subthreshold membrane potential oscillations still remained.

processes (cf. Oka and Ichikawa, 1991). From their morphological features and locations, all the intracellularly labeled TN cells in the present study could be identified as type I TN cells of Oka et al., which are immunoreactive to GnRH (Oka et al., 1986; Oka and Ichikawa, 1990, 1991, 1992). When the intracellular dye injection was confined to a single cell, the labeled cell appeared singly; that is, there was no dye coupling. This result agrees with the lack of gap junctions among the neighboring TN cells (Oka and Ichikawa, 1991) and the lack of synchronization of neighboring units (see Fig. 9C). Thus, it may be concluded that the TN-GnRH cells usually are not electrotonically coupled with each other.

Morphological characteristics common to all the labeled TN cells were the numerous dendritic branches in the vicinity of the cell bodies and the olfactory bulb (Fig. $11 A, B$ ), and relatively thicker axons (arrowheads in Fig. 11A,B) that arch through the ventral telencephalon and preoptic area to project caudally (Figs. 12-15). Usually, the axon gave off several thick and thin collaterals immediately after leaving the soma. These axon collaterals ran caudally and branched in the ventral telencephalon and preoptic area. In all of the labeled TN cells, some of these axon collaterals turned rostroventrally and entered the optic nerve (arrowheads in Figs. 12-14, ON), while other branches projected farther caudally, or in some cases rostrally, to innervate all the areas where dense $\mathrm{GnRH}$-ir fibers have been dem- 


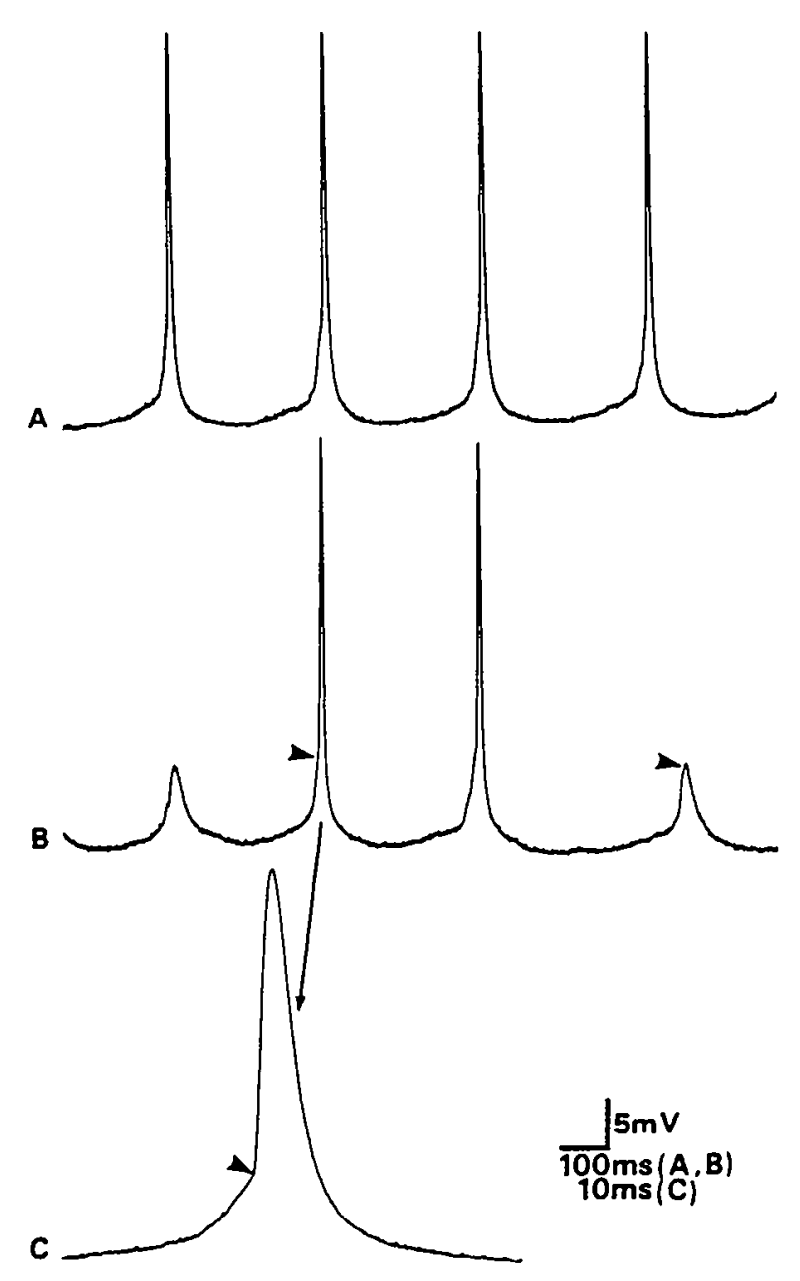

Figure 7. Intracellular recordings of beating discharge mode. $A$, The gradual depolarizations during interspike intervals are less prominent than those of other beating units in Figures 1 and 4-6. Inflections of spikes in their rising phase (arrowheads) are evident $(B, C)$, and the spikes often fail at these inflections $(B)$.

onstrated previously (Oka and Ichikawa, 1990). These include ventral and dorsal telencephalic areas, preoptic areas, thalamus, inferior lobe of hypothalamus, midbrain tegmentum, torus semicircularis, and optic tectum (Figs. 12-15; for the brain atlas, sec Oka and Ichikawa, 1990). Projection areas of a single TN cell are considerable. Figures 12,13, and 15 illustrate labeled profiles after unilateral single-cell injections. In these cases, fragments of labeled profiles were observed in all the sagittal sections on both sides of the brain except for the most lateral part, 100$300 \mu \mathrm{m}$ from the lateral edge of the brain. The contralaterally projecting axons crossed at various levels, for example, in the anterior commissure, posterior commissure, tectal commissure, and ventral tegmentum (solid triangles in Figs. 12-14). Rostrocaudally, the projection areas usually ranged from the olfactory bulb to the midbrain or medulla, and in some cases, as far as the rostral spinal cord (Fig. 12A). This explains how a small number of TN-GnRH cells (10-20 on each side; Oka ct al., 1986) can be the source of widespread GnRH-ir fibers. Thus, the TN-GnRH cells may be one of the most widely projecting neurons throughout the vertebrate brains.

There were, however, some minor differences in the projection areas. The TN cell in Figure 12 mainly projected to the olfactory bulb, midbrain tegmentum, optic tectum, and medulla

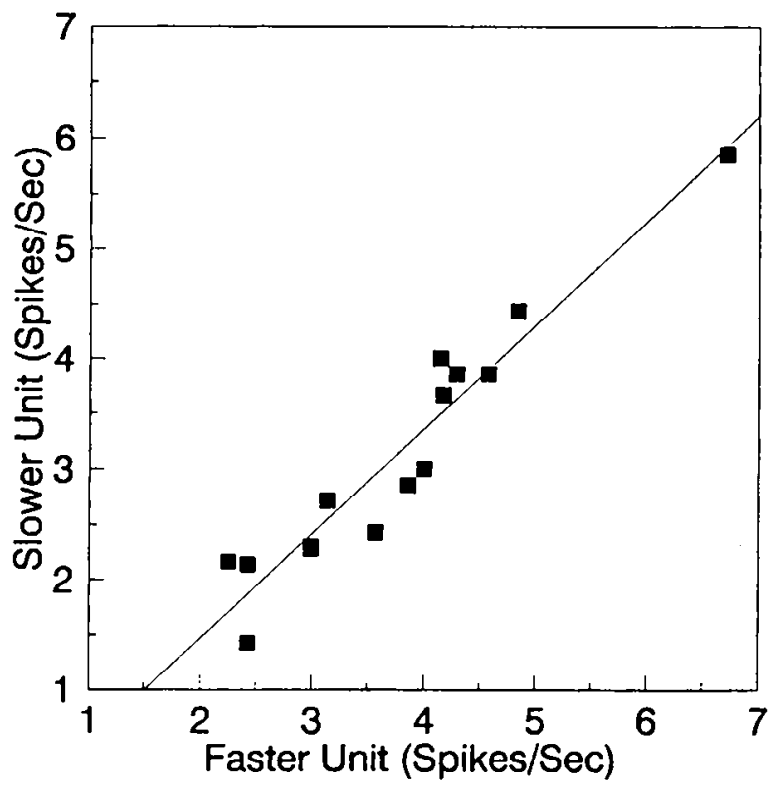

Figure 8. Relationship between frequencies of two different beating units recorded intracellularly from same preparations. There is a significantly $(P<0.001)$ positive correlation between the two $(r=0.92$, $Y=0.95 X-0.43)$, indicating that the different units recorded from the same preparation show similar discharge frequencies.

A
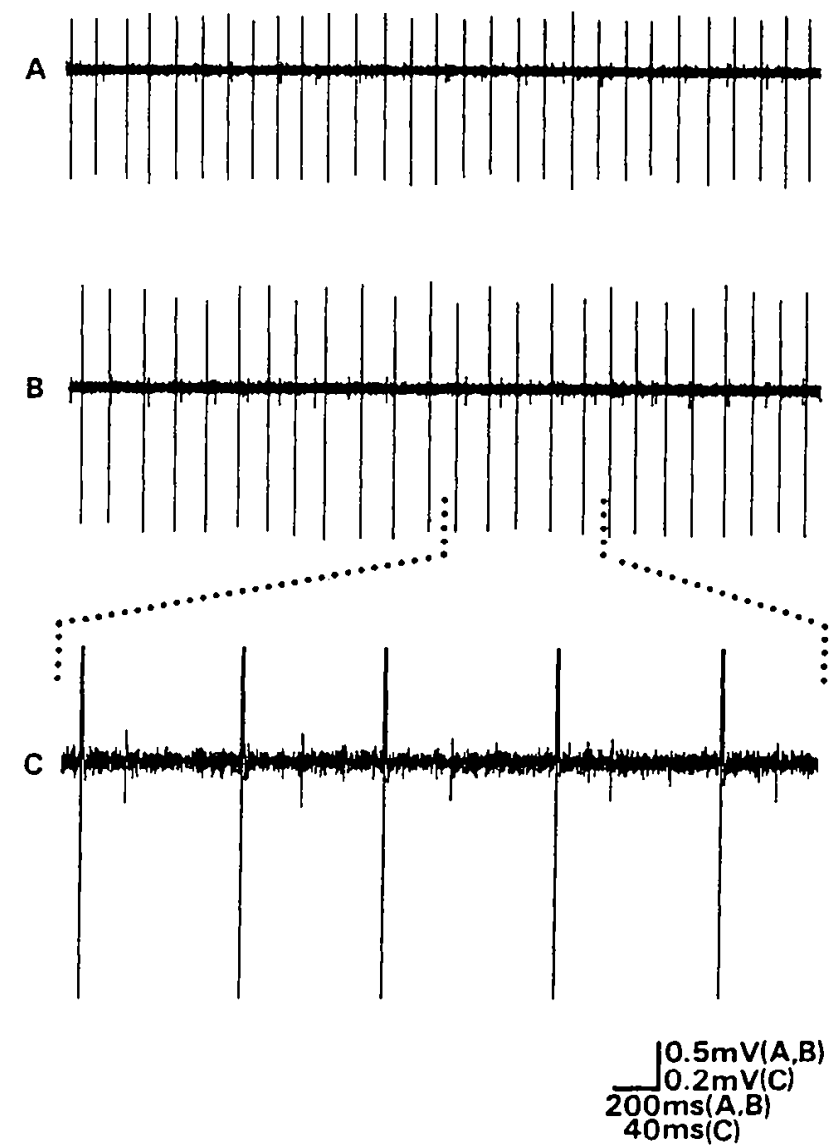

Figure 9. Spontaneous activities of TN-GnRH cells recorded extracellularly. The traces in $A$ and $B$ are recorded from different units in the same preparation. Both show beating discharge pattern of similar frequencies (about 8 spikes/sec). C shows an expanded tracc of the dotted part of $B$. Activities of adjacent units are simultaneously recorded as smaller spikes. Note that these simultaneously recorded units do not discharge synchronously with the larger unit. 

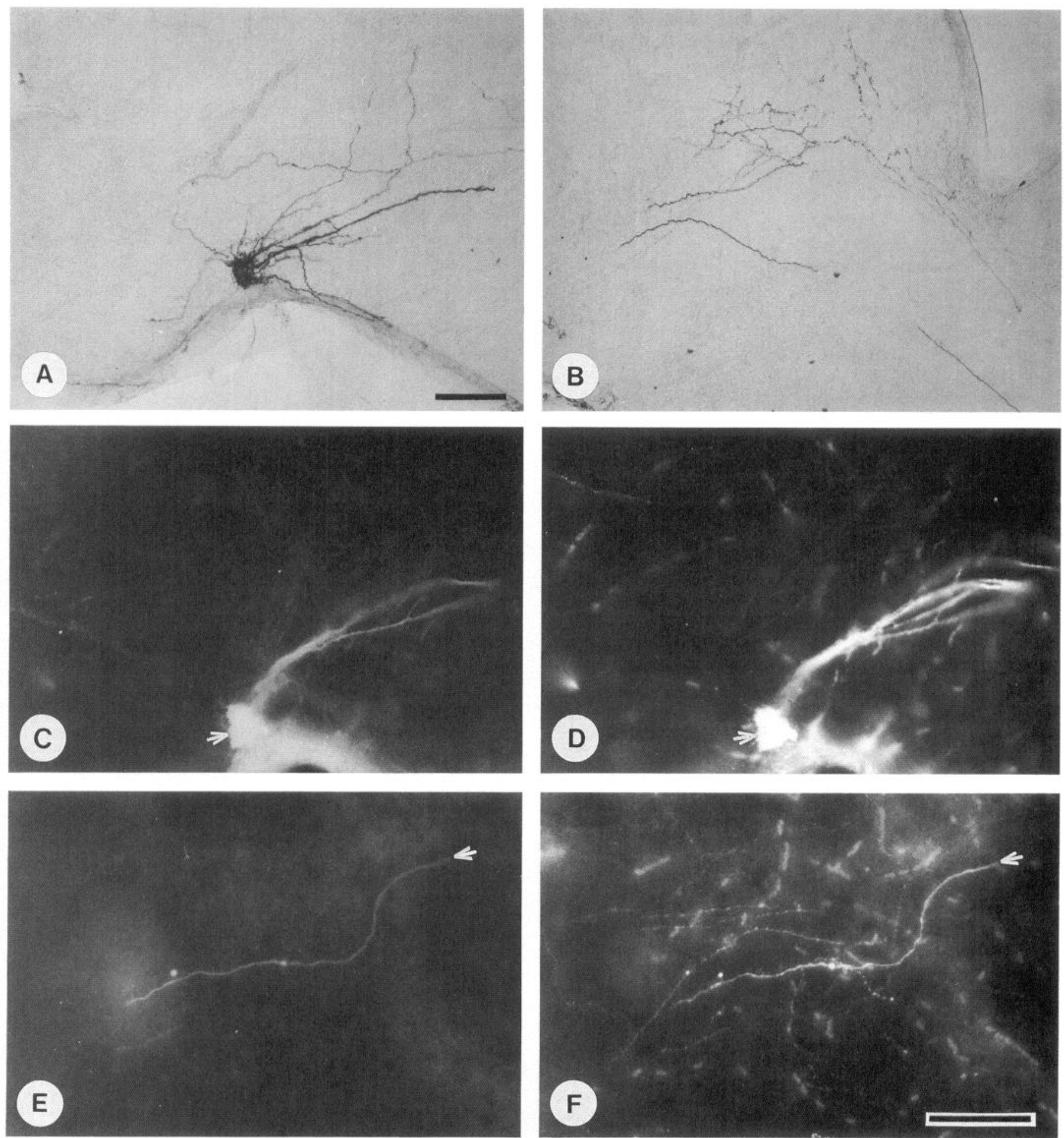

Figure 10. Photomicrographs of sagittal sections showing intracellularly labeled profiles $(A$ and $B)$ and double-labeled profiles $(C-F)$. $A$ shows a TN cell injected with biocytin, and $B$ shows labeled fibers in the posterior dorsal telencephalon arising from the cell body in $A$. Serial sections including the cell body and fibers in $A$ and $B$ were reconstructed and are shown in Figures $11 A$ and $14 A$. $C$ and $E$ show neurobiotin-injected, TRlabeled cell body and fibers ( $\mathrm{G}$ excitation), while $D$ and $F$ show GnRH-ir FITC-labeled cell bodies and fibers (B excitation) demonstrated on the same sections ( $C, D$ and $E, F$ are identical sections, respectively). The arrows in $C-F$ show double-labeled profiles. Meningeal membrane immediately ventral to the cell body shows autofluorescence $(C$ and $D)$. Scale bars: $A$ and $B, 100 \mu \mathrm{m} ; C-F, 100 \mu \mathrm{m}$.

on both sides and to the telencephalon of contralateral side, but not to the ipsilateral telencephalon. The cell in Figure 13, on the other hand, projected densely to the ipsilateral telencephalon but relatively sparsely to the contralateral side. The cells in
Figure 14, $A$ and $B$, projected densely to the caudoventral part of the dorsal telencephalon and to the optic tectum but less densely to the other areas. The cell in Figure 15 projected widely in the telencephalon, preoptic area, thalamus, torus semicir- 

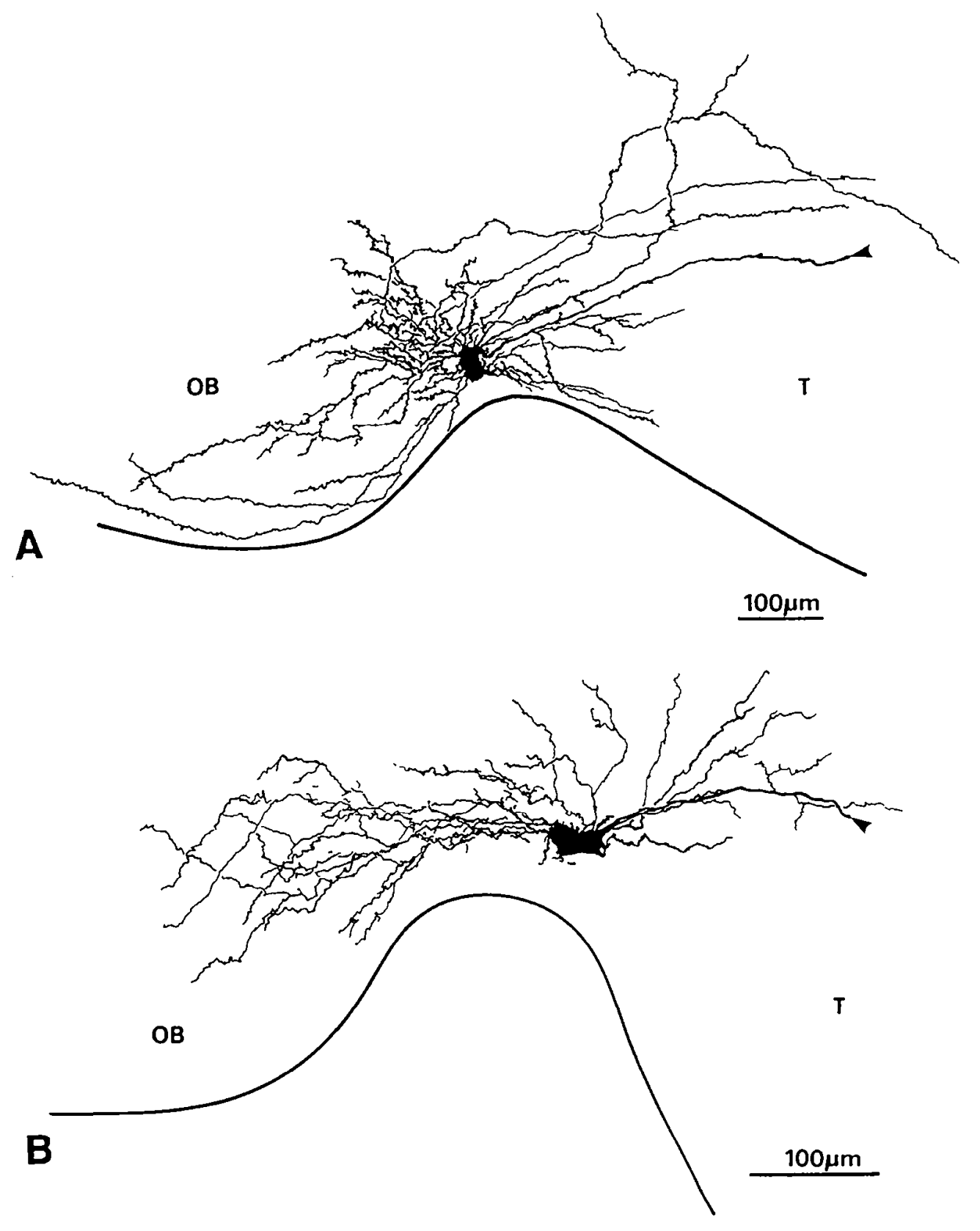

Figure 11. The cell body and proximal processes of TN-GnRH cclls injected with biocytin were reconstructed from serial sagittal sections. The diameters of the cell bodies range from 20 to $30 \mu \mathrm{m}$. They have irregular contour and numerous fine somatic processes. The arrowheads indicate the main axon. The cell body in $A$ corresponds to that of Figures $10 A$ and $14 A$. $O B$, olfactory bulb; $T$, ventral telencephalon. cularis, midbrain tegmentum, and medulla, but lacked projections to the optic tectum.

\section{Discussion}

The present article has demonstrated that the TN-GnRH cells have spontaneous discharge activities that are endogenous in origin and that each individual cell has multiple axonal branches that project to amazingly diverse regions of the CNS. These properties may be important for their possible role as a neuromodulator.

\section{Identification of $T N-G n R H$ cells}

The TN system of vertebrates has received much attention quite recently (see Demski and Schwanzel-Fukuda, 1987), since this system was found to contain GnRH-ir substance(s) (for review, see Silverman, 1988). However, the functional significance of this system is still poorly understood. We have recently dem- onstrated (Oka and Ichikawa, 1990, 1991, 1992; Yamamoto et al., 1991) that TN cells are a major component of the GnRH system and are structurally independent from the preoptic/hypophysial-GnRH system, which facilitates gonadotropin release from the pituitary. The GnRH-ir TN cells correspond to the type I TN cells of Oka et al. (1986), which have large cell bodies (20-30 $\mu \mathrm{m}$ in diameter) and make up a single large cluster just beneath the meningeal membrane on each side of the brain. It has been further confirmed that all the type I TN cells and no other cells in the neighboring areas are immunoreactive to $\mathrm{GnRH}$ (Oka and Ichikawa, 1992). The other category of TN cells, type II TN cells, are smaller (about $10 \mu \mathrm{m}$ in diameter), GnRHimmunoncgative (Oka and Ichikawa, 1991, 1992) cells that are scattered around the type I cell clusters. These project to the retina (Oka et al., 1986). Both types of TN cells are separated from other telencephalic cells by the medial olfactory tract fibers and other neuropil (see Fig. 1 of Oka and Ichikawa, 1991). Thus, 
Figure 12. Illustrations of intracellularly labeled TN-GnRH cell reconstructed from serial sagittal sections and drawn on a representative parasagittal plane. Biocytin was injected into a single neuron unilaterally $(A)$. The double arrowheads indicate the TN cell body. Many thin varicose fibers, presumably dendrites, invade the olfactory bulb $(O B)$. The axon branches into numerous collaterals immediately after leaving the soma; these run caudally and branch in the preoptic area. Some turn rostroventrally and enter the optic nerve $(O N$; the labeled fibers were cut at arrowheads during dissection) while other branches project to the dorsal thalamus, inferior lobe $(I L)$ of hypothalamus, midbrain tegmentum, and optic tectum $(O T)$. I abeled fibers were seen as far caudally as the medulla $(M)$ and the rostral spinal cord (this figure). In addition, some axons cross to the contralateral side $(B)$ at various levels, for example, in the anterior commissure, posterior commissure, tectal commissure, and ventral tegmentum (solid triangles), and project widely on the contralateral side. $T$, telencephalon; $P I T$, pituitary; $C O C b$, corpus cerebellum.
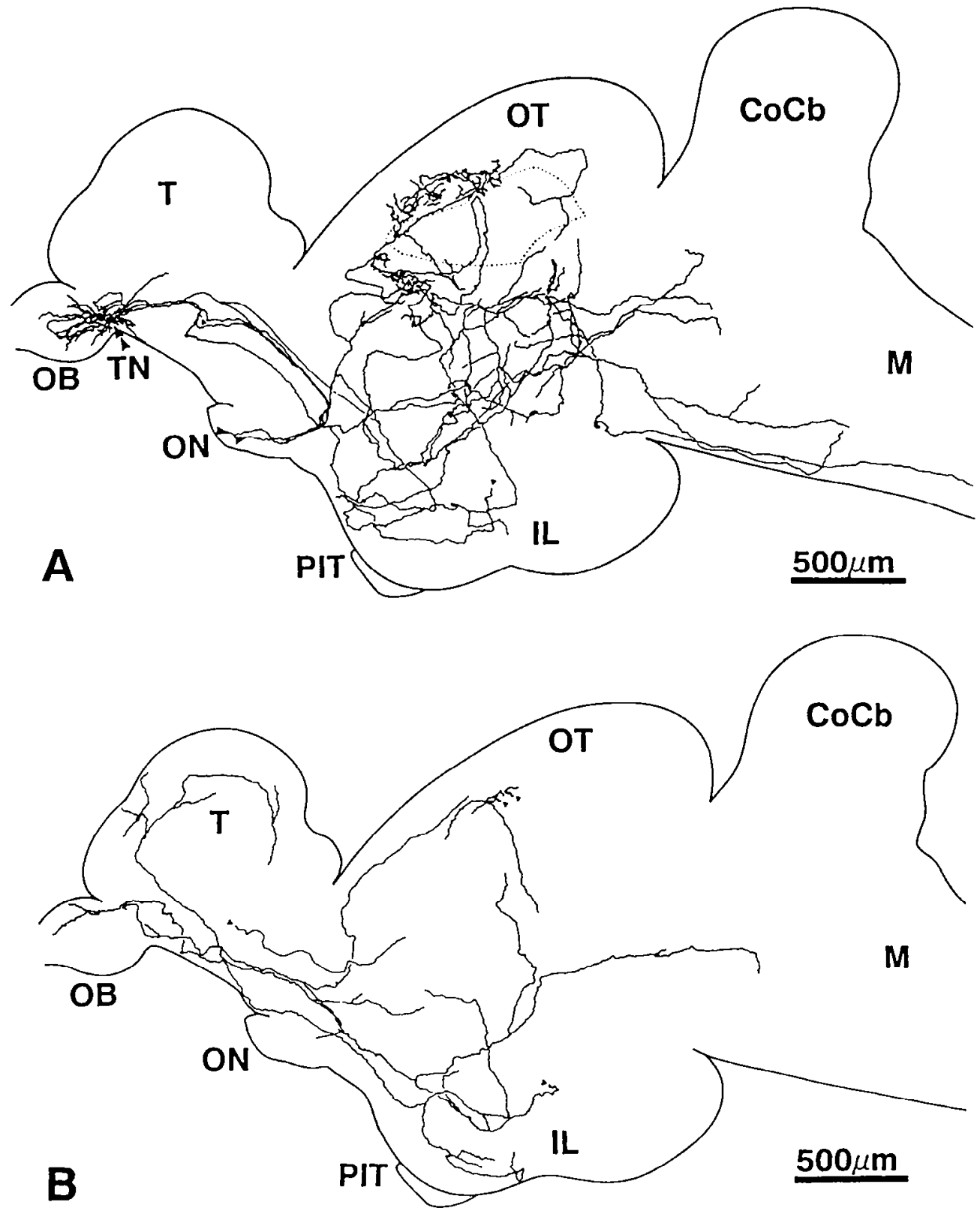

TN-GnRH cells could be quite easily identified during the experiments. In fact, all the cells recorded and stained in the present experiments could be identified as type I IN cells. Doublelabeling experiments using combined neurobiotin and $\mathrm{GnRH}$ immunocytochemistry (Fig. 10) clearly demonstrated the validity of this cell identification.

Subdivision of TN cell types has also been reported in other vertebrates including teleosts (Crapon de Caprona and Fritzsch, 1983; Matsutani et al., 1986; Stell et al., 1987; Uchiyama, 1990), elasmobranchs (Demski and Fields, 1988), amphibians (Wirsig and Getchell, 1986), birds (Wirsig-Wiechmann, 1990), and mammals (Wirsig and Lconard, 1986). The nature of GnRHimmunonegative TN cells is less well known except for possible immunoreactivity to vasoactive intestinal peptide and ChAT (rat, Schwanzel-Fukuda et al., 1986) or AChE activity (hamster, Wirsig and Lconard, 1986; amphibians, Wirsig and Getchell, 1986). They were not studied in the present study.

\section{Thpes of spontaneous discharges}

All the TN cells recorded in the present study showed spontaneous activities, which could be classified into three categories: beating, irrcgular, and bursting. Because of the low occurrence of the latter two modes, only the nature of the beating mode was analyzed in the present study.

Beating discharge mode. The beating discharge mode has been relatively well studied in molluscan neurons (Tauc, 1966; Junge and Moore, 1966; Alving, 1968; Connor, 1985). This type of activity has been shown to be endogenous to the neuron. That is, the beating activity is not driven by rhythmic synaptic inputs, and the cells function as pacemaker neurons. Regular spontaneous discharges of TN cells have also been notcd by previous workers who studied the TN cells of some teleosts (Fujita et al., 1985, 1991) and elasmobranchs (White and Meredith, 1987). However, they were not identified as GnRH-ir TN cells, and 

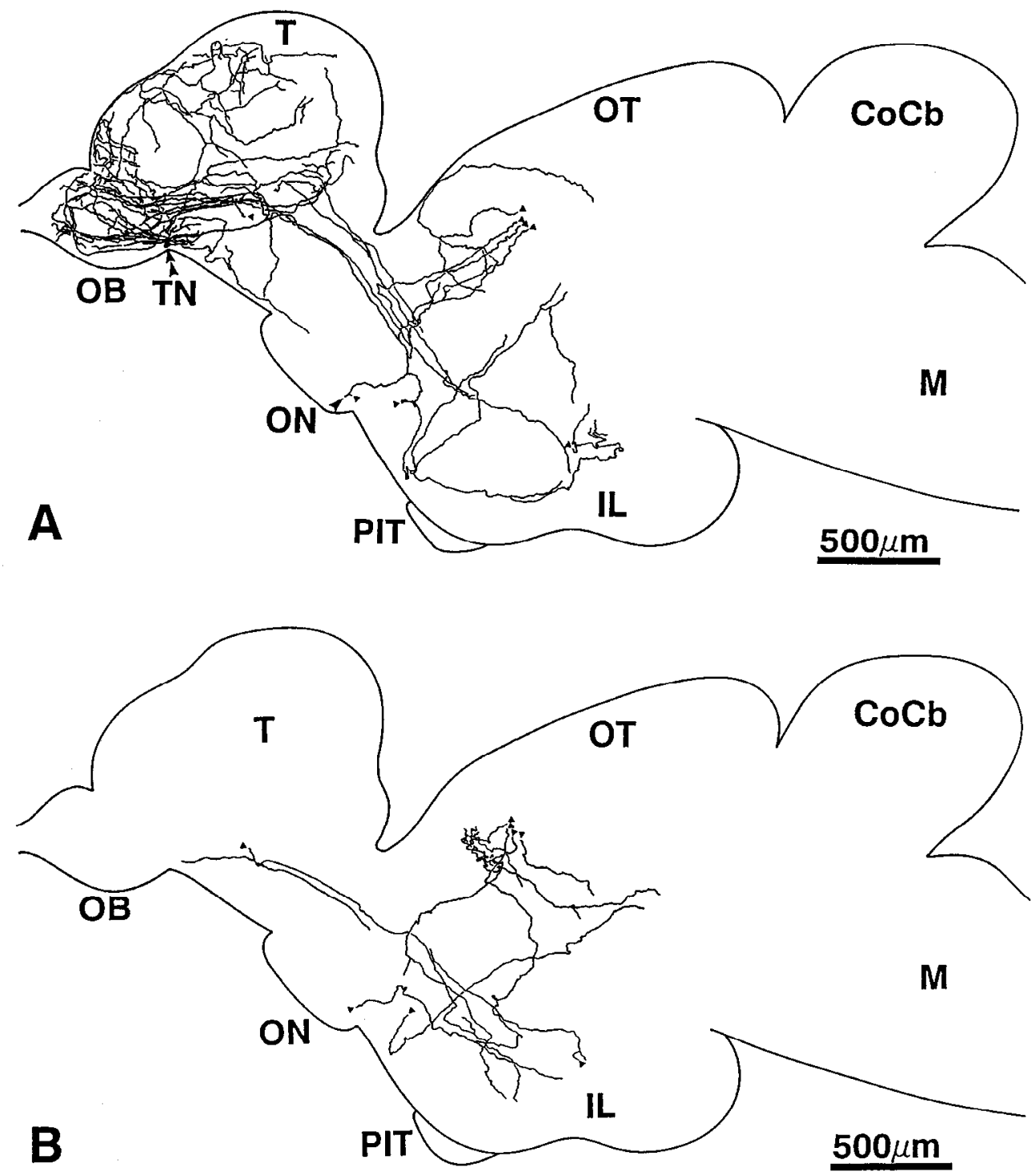

Figure 13. Illustrations of intracellularly labeled Tn-GnRH cell reconstructed from serial sagittal sections and drawn on a representative parasagittal plane. Biocytin was injected into a single neuron unilaterally. See Figure 12 caption for abbreviations and explanation. the intrinsic nature of spontaneous discharges was not examined.

In the present study, we have demonstrated that the beating rhythm of TN-GnRH cells is endogenous based upon the following criteria: (1) the discharge frequency was dependent on injected DC currents, (2) the beating rhythm was reset by current pulse injections, and (3) the pacemaker activities persisted under synaptically isolated conditions. It has been suggested that the low-frequency, repetitive discharge of the kind observed in molluscan neurons such as L11 can be predicted using the inward $\mathrm{Na}^{+}$and the fast (A current, $I_{\mathrm{A}}$ ) and delayed $\mathrm{K}^{+}$outward currents in combination with an inward leakage current (Connor, 1978). $I_{\mathrm{A}}$ is considered to play an important role in allowing neurons to encode graded depolarizations into spike train information (Rogawski, 1985). It has been reported that a persistent inward calcium current and $I_{\mathrm{A}}$ are in fact involved in the generation of beating discharge activity of the rat locus coeruleus neurons (Williams et al., 1984) and histaminergic tuberomammillary neurons of the rat hypothalamus (Haas and Reiner, 1988). In other examples of beating pacemaker cells, involvement of low-voltage-activated calcium current and $I_{\mathrm{A}}$ (serotonergic neurons of the dorsal raphe, Aghajanian, 1990) and low- and high-voltage-activated calcium currents and inward rectifiers (midbrain dopaminergic neurons, Grace and Onn, 1989) are also implicated. Thus, it will be an important aspect of future studies to determine the involvement of various ionic currents in the beating discharge mode of TN-GnRH cells.

The spike duration of TN-GnRH cells, especially during the beating mode, was long compared to that of typical axonal $\mathrm{Na}^{+}$ spikes. This may imply a contribution of high-voltage-activated calcium currents to the spike generation, although the shoulder on the repolarization phase of the action potential (Williams et al., 1984; Bourque and Renaud, 1985; Renaud, 1987; Sànchez and Ribas, 1991; Yung et al., 1991) was not prominent in the present experimental conditions. The long spike duration may also depend on the nature of conductances involved in the repolarization phase of the action potential. It has been suggested that failure of spike propagation at highly branched axonal network is less likely to occur with a broad action potential (Westerfield et al., 1978). Because TN-GnRH cells have highly branched axons, the long duration of action potential may give a good safety margin for impulse propagation.

Irregular and bursting discharge modes. Although the nature of these discharge modes could not be studied in detail, it is 


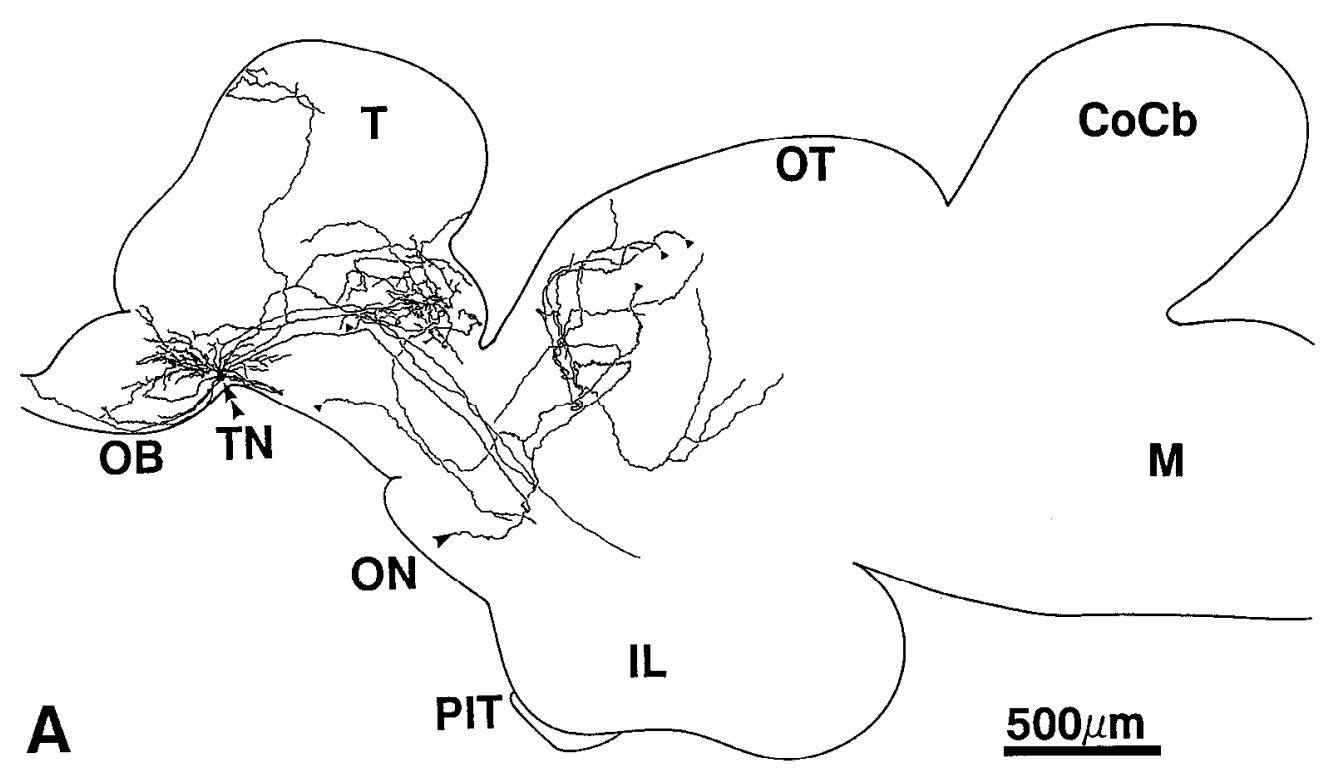

Figure 14. Illustrations of intracellularly labeled TN-GnRH cells reconstructed from serial sagittal sections and drawn on a representative parasagittal planc. Biocytin was injected into a single neuron on each side. See Figure 12 caption for abbreviations and explanation.

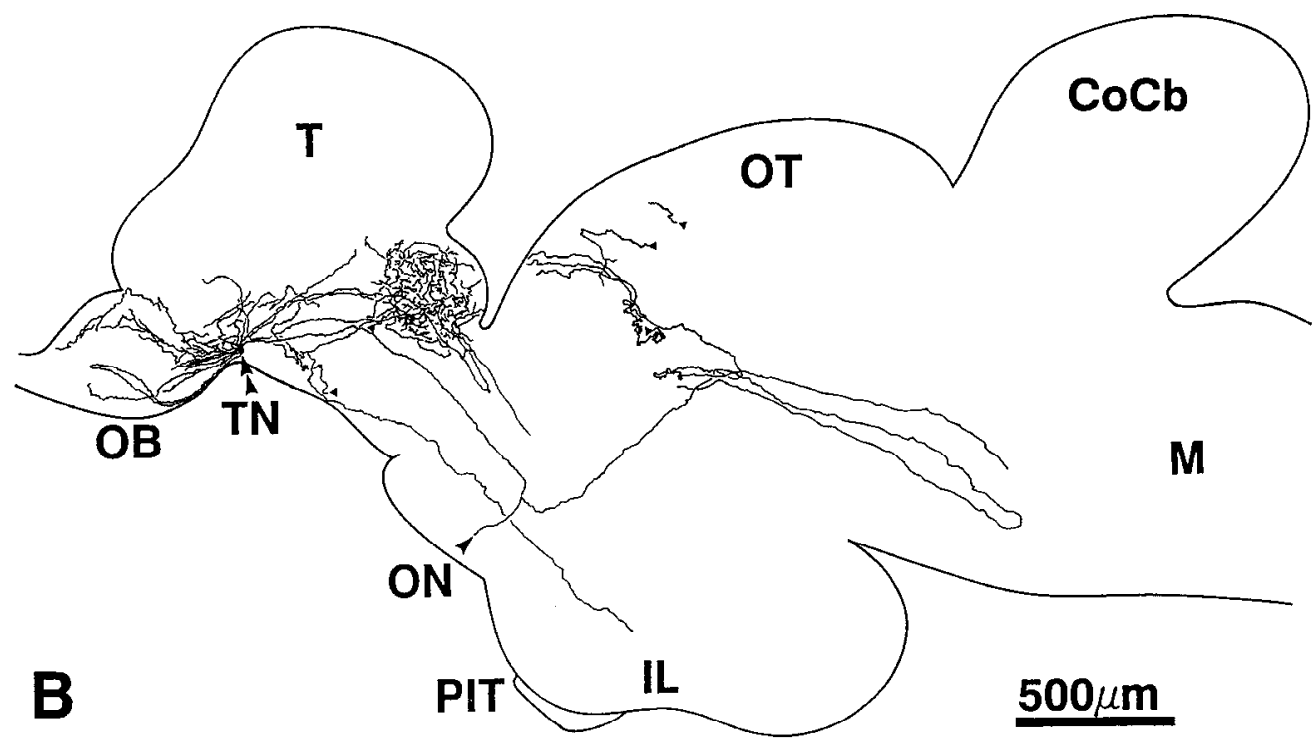

possible that the ionic mechanisms underlying these discharge modes are different from those of the beating discharge mode. The irregular discharge mode was characterized by short-duration spikes with fast afterhyperpolarization, while the bursting discharge mode was characterized by acceleration and broadening of spikes. Acceleration of spikes during bursting has been observed in bursting pacemaker neurons such as crustacean X-organ neurons (Martinez et al., 1991) and has been ascribed to the modification of $\mathrm{K}^{+}$current kinetics by $\mathrm{Ca}^{2+}$ during the burst. The spike broadening during bursting has been reported to result from progressive inactivation of the delayed-rectifier potassium current (Aldrich et al., 1979). Bursting discharge with the above-mentioned characteristics has often been reported in neurosecretory neurons of both vertebrates and invertebrates (Aldrich et al., 1979; Renaud, 1987; Partridge and Swandulla, 1988; Benson and Adams, 1989; Martinez et al., 1991). In fact, it is generally accepted that periodic bursts of action potentials are more effective stimulus for the secretion of hormones than a regular pattern of firing (Dutton and Dyball, 1979; but see
Peng and Horn, 1991). It is therefore speculated that GnRH release from TN-GnRH cells and fibers may be facilitated during bursting discharge mode.

Although the occurrence of cells with bursting and irregular discharge modes was very low, such activities probably are not artifacts of electrode penetrations because the pattern of discharge was the same among different units in the identical preparation. Furthermore, similar transitions between beating and bursting discharge modes have been reported in other putative neuromodulator systems, for example, the rat nigral dopamine neurons (Grace and Bunney, 1983, 1984a,b), and the rat noradrenergic neurons of the locus coeruleus (Marshall and Finlayson, 1988). In the former case, calcium ion has been suggested to play an important role in the transition between these two modes (Grace and Bunney, 1984a,b). In the rat magnocellular neuroendocrine cells, $\mathrm{Ca}^{2+}$ influx and $\mathrm{Ca}^{2+}$-dcpcndent spike aftercurrent are thought to play essential roles in burst generation (Bourque, 1986; Andrew, 1987). In molluscan pacemaker neurons, it has been demonstrated that the $\mathrm{Ca}^{2+}$ conductance and 


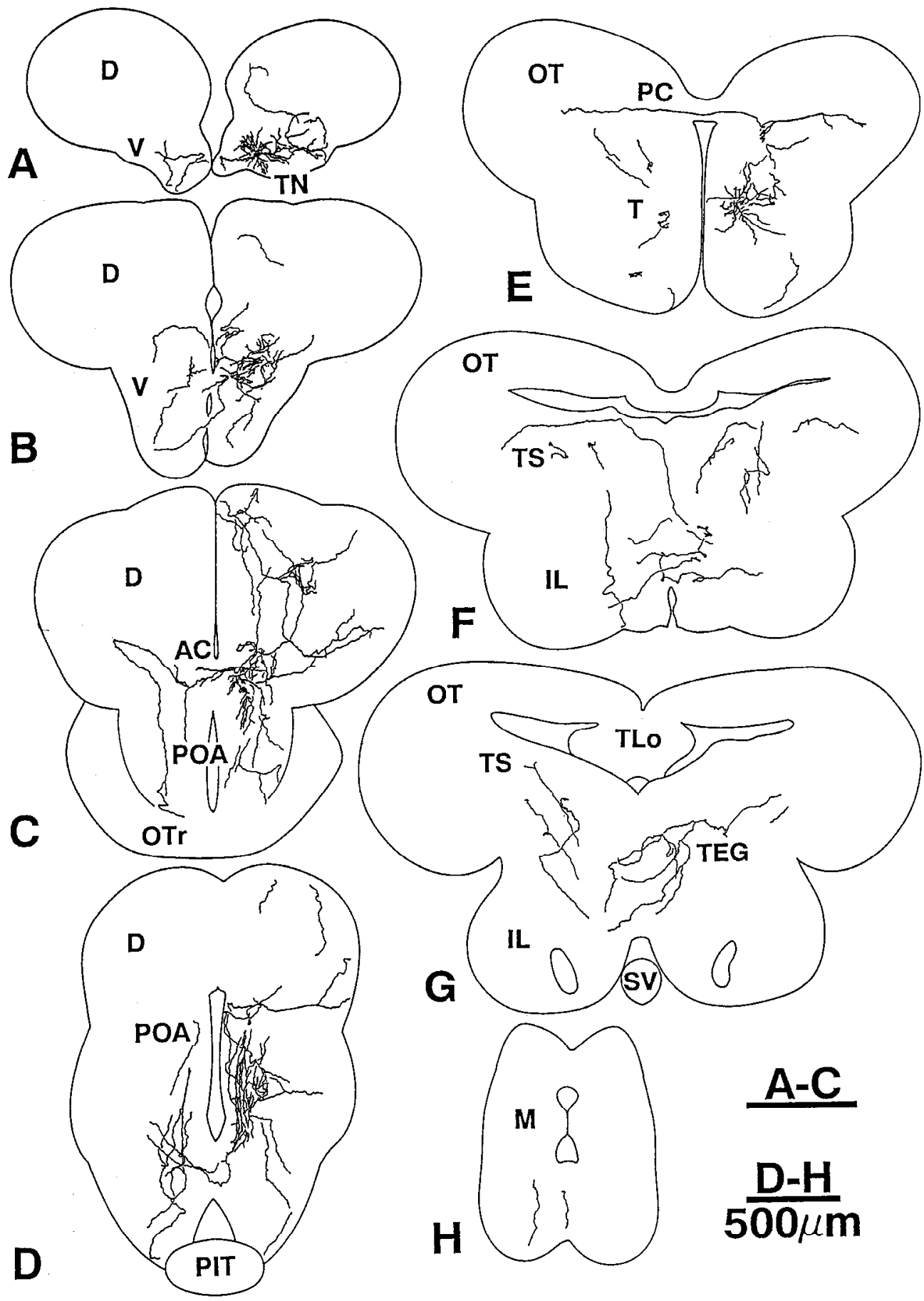

Figure 15. Illustrations of intracellularly labeled TN-GnRH cells on frontal sections. For each illustration, drawings of five $(A-F, H ; 320 \mu \mathrm{m}$ in total thickness) or $15(G ; 960 \mu \mathrm{m}$ in total thickncss) consccutive frontal scctions arc reconstructed and are projected on representative frontal sections. There is a gap of $640 \mu \mathrm{m}$ between $G$ and $H$. Biocytin was injected into a single neuron unilaterally. The cell body is shown in $A(T N)$. The labeled fibers project bilaterally in various brain regions. Compare this figure with the distribution of GnRH cell bodies and fibers reported by Oka and Ichikawa (1990, their Fig. 1). $D$, dorsal telencephalon; $V$, ventral telencephalon; $A C$, anterior commissure; $P O A$, preoptic area; $O T r$, optic tract; $P I T$, pituitary; $O T$, optic tectum; $P C$, posterior commissure; $T$, thalamus; $T S$, torus semicircularis; $I L$, inferior lobe of hypothalamus; $T L O$, torus longitudinalis; $T E G$, midbrain tegmentum; $S V$, saccus vascularis; $M$, medulla. Nuclear boundaries are not indicated for clarity. For the brain atlas, see Oka and Ichikawa (1990). the $\mathrm{Ca}^{2+}$-activated $\mathrm{K}^{+}$conductance are appreciably larger in the bursting pacemaker neurons $\mathrm{R} 15$ than in the beating pacemaker neuron L11, and these are quantitative rather than qualitative differences in membrane and cytoplasmic properties (Gormann and Hermann, 1982). Thus, it is possible that TN-GnRH cells undergo transitions among different discharge modes via quantitative changes, or modulation, of intrinsic ionic channel properties, which might arise from synaptic or hormonal inputs to TN-GnRH cells. Conventional synaptic inputs to TN cells have been demonstrated ultrastructurally (Matsutani et al., 1986; Zheng et al., 1990; Oka and Ichikawa, 1991) or electrophysiologically (Fujita et al., 1985; White and Meredith, 1987) or by retrograde tracing method (von Bartheld et al., 1986). There are at least two morphologically distinct synaptic inputs on TNGnRH cells (Matsutani et al., 1986; Oka and Ichikawa, 1991). In addition, there may be nonsynaptic inputs onto the TNGnRH cells (see Thureson-Klein and Klein, 1990).

An interesting and possibly important implication of the transition among different discharge modes is that TN-GnRH cells may release $\mathrm{GnRH}$ during bursting discharge modes whereas they release other nonpeptidergic cotransmitters during beating mode. Similar possibility has been suggested in some neuronal systems such as Aplysia neurons (Whim and Lloyd, 1989), preganglionic C-neurons of the bullfrog (Peng and Horn, 1991), and noradrenergic neurons of locus coeruleus (Marshall and Finlayson, 1988). It has been reported that goldfish TN cells are 
also immunoreactive to FMRFamide and the $\mathrm{N}$-terminal region of substance $\mathrm{P}$ in addition to $\mathrm{GnRH}$; it is likely that other conventional transmitters may yet be identified in the TN (Stell et al., 1987). The present in vitro preparation should prove to be useful for testing this possibility, because not only can the spontaneous discharge modes be modified experimentally, but GnRH release into the perfusing solution can be measured simultaneously in the same preparation.

\section{GnRH as a neuromodulator}

We have proposed that GnRH originating from TN cells does not function as a hypophysiotropic hormone but rather as a neuromodulator (see above and Oka, 1992). In fact, we have demonstrated that TN-GnRH cells of the dwarf gourami show ultrastructural features indicative of high occurrence of exocytosis (Oka and Ichikawa, 1991) and fiber varicosities, which are filled with GnRH-ir dense-cored vesicles (Oka and Ichikawa, 1992). However, we could find no evidence of GnRH-ir synapses that are characterized by active zones. Thus, we suggested that $\mathrm{GnRH}$ is released nonsynaptically from dense-cored vesicles containing fiber varicosities and that it exerts its modulatory action on $\mathrm{GnRH}$ receptors located on nearby as well as distant target neurons (Oka and Ichikawa, 1992).

Although the possible neuromodulator functions of $\mathrm{GnRH}$ have been relatively well studied in peripheral ganglia (for reviews, see Brown, 1983, 1988; Jones, 1987), much less information is available in the CNS (Wong et al., 1990). In the rat hippocampus, GnRH induces a long-lasting depolarization associated with increased input resistance, a decrease in the afterhyperpolarization following a train of action potentials, and a reduction in accommodation of repetitive cell discharge (Wong et al., 1990). In the teleost retina, which receives dense projection of GnRH fibers arising from TN cells, TN-GnRH fibers are known to synapse on dopaminergic interplexiform cells (Zucker and Dowling, 1987), and GnRH and other neuropeptides affect the retinal ganglion cell activity (Walker and Stell, 1986). Thus, it will be an interesting future project to study neuromodulatory action of $\mathrm{GnRH}$ on $\mathrm{GnRH}$ target cells (such as olfactory bulb, ventral telencephalon, etc.) and its relation to various spontaneous discharge modes by taking advantage of the whole-brain in vitro preparation.

\section{Morphology of TN-GnRH cells}

To our knowledge the present article may be the first report to reveal complete profiles of a single peptidergic neuron including its axonal projections throughout the brain. The projection areas of TN-GnRH cells ranged from the olfactory bulb to the spinal cord, and from the medial to the most lateral part of the brain of ipsilateral as well as contralateral sides. Thus, TN-GnRH cells may be one of the most widely projecting neuronal systems in the vertebrate brain. The morphology of the cell bodies and proximal processes of carp TN cells has been described first by Fujita et al. (1985). Although it is not clear whether they are immunoreactive to GnRH, they look similar to the TN-GnRH cells of the dwarf gourami; both TN cells bear numerous fine and tortuous dendritic processes and somatic processes. Some of these somatic processes probably take part in the formation of "glomeruloid complex" (see Oka and Ichikawa, 1991), which may be involved in nonsynaptic intercellular communications.

There has been only one previous report on the projection of TN cells (in goldfish, von Bartheld and Meyer, 1986), which, however, used extracellular anterograde cobalt filling method.
They reported on several different projection pathways of TN cells. However, because of the technical limitations of extracellular filling, it was not clear whether these projections arise from individual cells or not. When we compare their results with ours, it should be also noted that their extracellular filling method cannot differentiate between projections of different TN cell populations, that is, GnRH-immunoreactive and -immunonegative cells. We have demonstrated in the present study that single TN-GnRH cells project widely in various brain regions. Therefore, it may be possible that different projection pathways reported in the goldfish (von Bartheld and Meyer, 1986) originated from single TN cells.

\section{Common features of peptidergic and monoaminergic systems}

Interestingly, physiological and morphological features similar to those of TN-GnRH cells have been reported in other putative neuromodulator systems. These include serotonergic neurons in the dorsal raphe (Aghajanian, 1990), noradrenergic neurons in the locus coeruleus (Williams et al., 1984; Marshall and Finlayson, 1988), dopaminergic neurons in the substantia nigra and ventral tegmental area (Grace, 1988, 1991), and histaminergic neurons in the hypothalamus (Haas and Reiner, 1988). All of these neurons show spontaneous beating discharge patterns that probably arise from intrinsic ionic channel properties of their own. Presumably, such endogenous rhythmic discharge patterns are one of the essential features common to all peptidergic and monoaminergic modulator neurons. Similarities between these modulatory neurons and the TN-GnRH system are also evident in their patterns of projections. Although there has been no intracellular staining and tracing of axonal projections comparable to the present study, it has been demonstrated by immunocytochemical methods that serotonergic, noradrenergic, dopaminergic, and histaminergic projections are widely distributed throughout the brain while these substances are synthesized by rather small numbers of neurons whose soma are restricted to discrete loci (Nieuwenhuys, 1985; Wada et al., 1991). Neuronal systems showing morphological features like these correspond to the "nonspecific or diffuse neuronal systems" as described by Nicoll et al. (1990). Thus, the morphological and physiological characteristics of TN-GnRH cells, as demonstrated in the present study, are not specific to this system but are features that are shared with other modulator neurons, including monoaminergic and peptidergic neurons.

\section{Hypothesis}

From the results of the present studies on the electrical activities and morphology of TN-GnRH cells of a fish brain in vitro and those of our previous studies (Oka and Ichikawa, 1990, 1991, 1992; Yamamoto et al., 1991), we propose a general hypothesis regarding modulator neurons (cf. Fig. 4 of Oka, 1992). Modulator neurons have spontaneous oscillatory activities that originate from the intrinsic ionic channel properties of their own membranes. These ionic channel properties are themselves subject to modification by various extrinsic factors, for example, hormonal, pheromonal, environmental, and so on, which finally act on the modulator neurons through hormones or neurotransmitters. 'This may result in the ability of modulatory neurons to alter their own beating discharge frequencies or to switch among different discharge modes (see Spontaneous discharge frequencies and modes, in Results). In other words, the animal's physiological conditions may be encoded in the frequency and or pattern of discharge of modulator neurons. These modulator 
neurons, in turn, can regulate simultaneously the excitabilities of target neurons in a wide variety of brain regions via extensive, multiple axonal branches.

Given the above-mentioned fundamental similarities to other putative neuromodulator systems, as well as the obvious technical advantages afforded by the in vitro whole-brain preparation, the TN-GnRH cells of the dwarf gourami may prove to be an ideal model for detailing the general physiological mechanisms of modulatory systems.

\section{References}

Aghajanian GK (1990) Use of brain slices in the study of serotonergic pacemaker neurons of the brainstem raphe nuclei. In: Preparations of vertebrate central nervous system in vitro (Jahnsen $\mathrm{H}$, ed), pp 2547. Chichester: Wiley.

Aldrich RW, Getting PA, Thompson SH (1979) Mechanism of frequency-dependent broadening of molluscan neurone soma spikes. $J$ Physiol (Lond) 291:531-544.

Alreja M, Aghajanian GK (1991) Pacemaker activity of locus coeruleus neurons: whole-cell recordings in brain slices show dependence on cAMP and protein kinase A. Brain Res 556:339-343.

Alving BO (1968) Spontaneous activity in isolated somala of Aplysia pacemaker neurons. J Gen Physiol 51:29-45.

Andrew RD (1987) Endogenous bursting by rat supraoptic neuroendocrine cells is calcium dependent. J Physiol (Lond) 384:451-465.

Andrew RD (1989) Oscillatory activity in supraoptic nucleus. In: Neuronal and cellular oscillators (Jacklet JW, ed), pp 121-147. New York: Dekker.

Benson JA, Adams WB (1989) Ionic mechanisms of endogenous activity in molluscan burster neurons. In: Neuronal and cellular oscillators (Jacklet JW, ed), pp 87-120. New York: Dekker.

Bourque CW (1986) Calcium-dependent spike after-current induces burst firing in magnocellular neurosecretory cells. Neurosci Lett 70: 204-209.

Bourque CW, Renaud LP (1985) Calcium-dependent action potentials in rat supraoptic neurosecretory neurones recorded in vitro. J Physiol (Lond) 363:419-428.

Brown DA (1983) Slow cholinergic excitation-a mechanism for increasing neuronal excitement. Trends Neurosci 6:302-307.

Brown DA (1988) M-Currents: an update. Trends Neurosci 11:294299.

Connor JA (1978) Slow repetitive activity from fast conductance changes in neurons. Fed Proc 37:2139-2145.

Connor JA (1985) Neural pacemakers and rhythmicity. Annu Rev Physiol 47:17-28.

Crapon de Caprona M-D, Fritzsch B (1983) The development of the retinopetal nucleus olfacto-retinalis of two cichlid fish as revealed by horseradish peroxidase. Dev Brain Res 11:281-301.

Demski LS, Fields RD (1988) Dense-cored vesicle-containing components of the terminal nerve of sharks and rays. J Comp Neurol 278:604-614.

Demski LS, Schwanzel-Fukuda M (1987) The terminal nerve (nervus terminalis). Structure, function, and evolution. Ann NY Acad Sci 519:1-469.

Dutton A, Dyball REJ (1979) Phasic firing enhances vasopressin release from rat neurohypophysis. J Physiol (Lond) 290:433-440.

Fujita I, Satou M, Ueda K (1985) Ganglion cells of the terminal nerve: morphology and electrophysiology. Brain Res 335:148-152.

Fujita I, Sorensen PW, Stacey NE, Hara TJ (1991) The olfactory system, not the terminal nerve, functions as the primary chemosensory pathway mediating responses to sex pheromones in male goldfish. Brain Behav Evol 38:313-321.

Gormann ALF, Hermann, A (1982) Quantitative differences in the currents of bursting and beating molluscan pace-maker neurones. J Physiol (Lond) 333:681-699.

Grace AA (1988) In vivo and in vitro intracellular recording from rat midbrain dopamine neurons. Ann NY Acad Sci 537:51-76.

Grace AA (1991) Regulation of spontaneous activity and oscillatory spike firing in rat midbrain dopamine neurons recorded in vitro. Synapse 7:221-234.

Grace AA, Bunney BS (1983) Intracellular and extracellular electrophysiology of nigral dopaminergic neurons-1. Identification and characterization. Neuroscience 10:301-315.
Grace AA, Bunney BS (1984a) The control of firing pattern in nigral dopamine neurons: single spikc firing. J Ncurosci 4:2866-2876.

Grace AA, Bunney BS (1984b) The control of firing pattern in nigral dopamine neurons: burst firing. J Neurosci 4:2877-2890.

Grace AA, Onn S-P (1989) Morphology and electrophysiological properties of immunocytochemically identified rat dopamine neurons in vitro. J Neurosci 9:3463-3481.

Haas HL, Reiner PB (1988) Membrane properties of histaminergic tuberomammillary neurones of the rat hypothalamus in vitro. J Physiol (Lond) 399:633-646.

Hille B (1992) Modulation, slow synaptic action and second messengers. In: Ionic channels of excitable membranes, 2d ed, pp 170-201. Sunderland, MA: Sinauer.

Horikawa K, Armstrong WE (1988) A versatile means of intracellular labeling: injection of biocytin and its detection with avidin conjugates. J Ncurosci Methods 25:1-11.

Jones SW (1987) Luteinizing hormone-releasing hormone as a neurotransmitter in bullfrog sympathetic ganglia. Ann NY Acad Sci 519: 310-322.

Junge D, Moore GP (1966) Interspike-interval fluctuations in Aplysia pacemaker neurons. Biophys J 6:411-434.

Kaczmarek LK, Levitan IB (1987) Neuromodulation. New York: Oxford UP.

Kita H, Armstrong W (1991) A biotin-containing compound $\mathrm{N}$-(2aminoethyl) biotinamide for intracellular labeling and neuronal tracing studies: comparison with biocytin. J Neurosci Methods 37:141150.

Llinàs R, Sugimori M (1980) Electrophysiological properties of in vitro Purkinje cell somata in mammalian cerebellar slices. J Physiol (Lond) 305:171-195.

Marshall KC, Finlayson PG (1988) Synaptic regulation of locus coeruleus neuronal activity. In: Neurotransmitters and cortical function (Avoli M, Reader TA, Dykes RW, Gloor P, eds), pp 373-390. New York: Plenum.

Martinez JJ, Onetti CG, Garcia E, Hernandez S (1991) Potassium current kinetics in bursting secretory neurons: effects of intracellular calcium. J Neurophysiol 66:1455-1461.

Matsutani S, Uchiyama H, Ito H (1986) Cytoarchitecture, synaptic organization and fiber connections of the nucleus olfactoretinalis in a teleost (Navodon modestus). Brain Res 373:126-138.

Nicoll RA, Malenka RC, Kauer JA (1990) Functional comparison of neurotransmitter receptor subtypes in mammalian central nervous system. Physiol Rev 70:513-565.

Nieuwenhuys R (1985) Chemoarchitecture of the brain. Berlin:Springer.

Oka Y (1991a) Intracellular recording and staining of terminal nerveGnRH cells in a fish brain in vitro. Soc Neurosci Abstr 17:1335.

Oka Y (1991b) The terminal nerve-GnRH cells have morphological and physiological characteristics relevant for a neuromodulator. Neurosci Res [Suppl] 16:S36.

Oka Y (1992) Gonadotropin-releasing hormone (GnRH) cells of the terminal nerve as a model neuromodulator system. Neurosci Lett 142:119-122.

Oka Y, Ichikawa M (1990) Gonadotropin-releasing hormone (GnRH) immunoreactive system in the brain of the dwarf gourami (Colisa lalia) as revealed by light microscopic immunocytochemistry using a monoclonal antibody to common amino acid sequence of GnRH. J Comp Neurol 300:51 1-522.

Oka Y, Ichikawa M (1991) Ultrastructure of the ganglion cells of the terminal nerve in the dwarf gourami (Colisa lalia). J Comp Neurol 304:161-171.

Oka Y, Ichikawa M (1992) Ultrastructural characterization of gonadotropin-releasing hormone ( $\mathrm{GnRH})$-immunoreactive terminal nerve cells in the dwarf gourami. Neurosci Lett 140:200-202.

Oka Y, Munro AD, Lam T (1986) Retinopetal projections from a subpopulation of ganglion cells of the nervus terminalis in the dwarf gourami (Colisa lalia). Brain Res 367:341-345.

Partridge LD, Swandulla D (1988) Calcium-activated non-specific cation channels. Trends Neurosci 11:69-72.

Peng Y, Horn JP (1991) Continuous repetitive stimuli are more effective than bursts for evoking LHRH release in bullfrog sympathetic ganglia. J Neurosci 11:85-95.

Raggenbass M, Goumaz M, Sermasi E, Tribollet E, Dreifuss JJ (1991) Vasopressin generates a persistent voltage-dependent sodium current in a mammalian motoneuron. J Neurosci 11:1609-1616. 
Renaud LP (1987) Magnocellular neuroendocrine neurons: update on intrinsic properties, synaptic inputs and neuropharmacology. Trends Neurosci 10:498-502.

Rogawski MA (1985) The A-current: how ubiquitous a feature of excitable cells is it? Trends Neurosci 8:214-219.

Sànchez D, Ribas J (1991) Properties and ionic basis of the action potentials in the periaqueductal grey neurones of the guinea-pig. $\mathrm{J}$ Physiol (Lond) 440:167-187.

Schwanzel-Fukuda M, Silverman AJ (1980) The nervus terminalis of the guinea pig: a new luteinizing hormone-releasing hormone (LHRH) neuronal system. J Comp Neurol 218:426-432.

Schwanzel-Fukuda M, Morrel JI, Pfaff DW (1986) Localization of choline acetyltransferase and vasoactive intestinal polypeptide-like immunoreactivity in the nervus terminalis of the fetal and neonatal rat. Peptides 7:899-906.

Silverman AJ (1988) The gonadotropin-releasing hormone (GnRH) neuronal systems: immunocytochemistry. In: The physiology of reproduction (Knobil E, Neil JD, eds), pp 1283-1304. New York: Raven.

Stell WK, Walker SE, Ball AK (1987) Functional-anatomical studies on the terminal nerve projection to the retina of bony fishes. Ann NY Acad Sci 519:80-96.

Tauc L (1966) Physiology of the nervous system. In: physiology of molluscan (Wilbur KM, Yonge CM, eds), pp 387-454. New York: Academic.

Thureson-Klein ÅK, Klein RL (1990) Exocytosis from neuronal large dense-cored vesicles. Int Rev Cytol 121:67-126.

Uchiyama H (1990) Immunohistochemical subpopulations of retinopetal neurons in the nucleus olfactoretinalis in a teleost, the whitespotted greenling (Hexagrammos stelleri). J Comp Neurol 293:5462.

von Bartheld CS, Meyer DL (1986) Tracing of single fibers of the nervus terminalis in the goldfish brain. Cell Tissue Res 245:143-158.

von Bartheld CS, Rickmann MJ, Meyer DL (1986) A light- and electron-microscopic study of mesencephalic neurons projecting to the ganglion of the nervus terminalis in the goldfish. Cell Tissue Res 246: 63-70.

Wada H, Inagaki N, Yamatodani A, Watanabe T (1991) Is the histaminergic neuron system a regulatory center for whole-brain activity? Trends Neurosci 14:415-418.
Walker SE, Stell WK (1986) Gonadotropin-releasing hormone (GnRF), molluscan cardioexcitatory peptide (FMRFamide), enkephalin and related neuropeptides affect goldfish retinal ganglion cell activity. Brain Res 384:262-273.

Westerfield M, Joyner RW, Moore JW (1978) Temperature-sensitive conduction failure at axon branch points. J Neurophysiol 41:1-8.

Whim MD, Lloyd PE (1989) Frequency-dependent release of peptide cotransmitters from identified cholinergic motor neurons in Aplysia. Proc Natl Acad Sci USA 86:9034-9038.

White J, Meredith M (1987) Synaptic interactions in the nervus terminalis ganglion of elasmobranchs. Ann NY Acad Sci 519:33-49.

Williams JT, North RA, Shefner SA, Nishi S, Egan TM (1984) Membrane properties of rat locus coeruleus neurones. Neuroscience 13: $137-156$.

Wirsig CR, Getchell TV (1986) Amphibian terminal nerve: distribution revealed by LHRH and AChE markers. Brain Res 385:10-21.

Wirsig CR, Leonard CM (1986) Acetyl cholinesterase and luteinizing hormone-releasing hormone distinguish separate populations of terminal nerve neurons. Neuroscience 19:719-740.

Wirsig-Wiechmann CR (1990) The nervus terminalis in the chick: a FMRFamide-immunoreactive and AChE-positive nerve. Brain Res 523:175-179.

Wong M, Eaton MJ, Moss RL (1990) Electrophysiological actions of luteinizing hormone-releasing hormone: intracellular studies in the rat hippocampal slice preparation. Synapse 5:65-70.

Yamamoto N, Oka Y, Amano M, Aida M, Hasegawa Y, Kawashima S (1991) Multiple GnRH neuronal systems in the dwarf gourami immunocytochemistry and radioimmunoassay. Proc Jpn Soc Comp Endocrinol 6:6.

Yung WH, Hausser MA, Jack JJB (1991) Electrophysiology of dopaminergic and non-dopaminergic neurones of the guinea-pig substantia nigra pars compacta in vitro. J Physiol (Lond) 436:643-667.

Zheng L-M, Pfaff DW, Schwanzel-Fukuda M (1990) Synaptology of luteinizing hormone-releasing hormone (LHRH)-immunoreactive cells in the nervus terminalis of the gray short-tailed opossum (Monodelphis domestica). J Comp Neurol 295:327-337.

Zucker CL, Dowling JE (1987) Centrifugal fibres synapse on dopaminergic interplexiform cells in the teleost retina. Nature 300:166168. 